\title{
Transient Climate Simulations with the HadGEM1 Climate Model: Causes of Past Warming and Future Climate Change
}

\author{
Peter A. Stott \\ Hadley Centre for Climate Prediction and Research, Met Office, University of Reading, Reading, Berkshire, \\ United Kingdom \\ GARETH S. JONES \\ Hadley Centre for Climate Prediction and Research, Met Office, Exeter, United Kingdom \\ JASON A. LOWE \\ Hadley Centre for Climate Prediction and Research, Met Office, University of Reading, Reading, Berkshire, \\ United Kingdom \\ Peter Thorne, Chris Durman, Timothy C. Johns, and Jean-Claude Thelen \\ Hadley Centre for Climate Prediction and Research, Met Office, Exeter, United Kingdom
}

(Manuscript received 22 June 2005, in final form 11 October 2005)

\begin{abstract}
The ability of climate models to simulate large-scale temperature changes during the twentieth century when they include both anthropogenic and natural forcings and their inability to account for warming over the last $50 \mathrm{yr}$ when they exclude increasing greenhouse gas concentrations has been used as evidence for an anthropogenic influence on global warming. One criticism of the models used in many of these studies is that they exclude some forcings of potential importance, notably from fossil fuel black carbon, biomass smoke, and land use changes. Herein transient simulations with a new model, the Hadley Centre Global Environmental Model version 1 (HadGEM1), are described, which include these forcings in addition to other anthropogenic and natural forcings, and a fully interactive treatment of atmospheric sulfur and its effects on clouds. These new simulations support previous work by showing that there was a significant anthropogenic influence on near-surface temperature change over the last century. They demonstrate that black carbon and land use changes are relatively unimportant for explaining global mean near-surface temperature changes.

The pattern of warming in the troposphere and cooling in the stratosphere that has been observed in radiosonde data since 1958 can only be reproduced when the model includes anthropogenic forcings. However, there are some discrepancies between the model simulations and radiosonde data, which are largest where observational uncertainty is greatest in the Tropics and high latitudes.

Predictions of future warming have also been made using the new model. Twenty-first-century warming rates, following policy-relevant emissions scenarios, are slightly greater in HadGEM1 than in the Third Hadley Centre Coupled Ocean-Atmosphere General Circulation Model (HadCM3) as a result of the extra forcing in HadGEM1. An experiment in which greenhouse gases and other anthropogenic forcings are stabilized at 2100 levels and held constant until 2200 predicts a committed twenty-second-century warming of less than $1 \mathrm{~K}$, whose spatial distribution resembles that of warming during the twenty-first century, implying that the local feedbacks that determine the pattern of warming do not change significantly.
\end{abstract}

\section{Introduction}

The global warming observed near the surface of the earth over the twentieth century did not occur at a

Corresponding author address: Peter A. Stott, Hadley Centre, Meteorology Bldg., University of Reading, Reading, Berkshire RG6 6BB, United Kingdom.

E-mail: peter.stott@metoffice.gov.uk constant rate; instead, there were two periods of warming in the early and later parts of the century, with a period of about $30 \mathrm{yr}$ in the middle of the century when temperatures cooled slightly (Jones and Moberg 2003). A large number of coupled general circulation oceanatmosphere model simulations now exist of climate change over the last century. Many of these simulations contain a selection of the most important climate forcings, both of anthropogenic and natural origin. As part 
of the Fourth Assessment Report of the Intergovernmental Panel on Climate Change (IPCC), 19 coupled atmosphere-ocean models have been run with a range of natural and anthropogenic forcings as part of the "Climate of the 20th Century" experiment. A subset of these models that have also been run with just natural forcings (omitting anthropogenic forcings; e.g., Broccoli et al. 2003; Meehl et al. 2004) support the conclusions of an earlier study based on the Third Hadley Centre Coupled Ocean-Atmosphere General Circulation Model (HadCM3) (Stott et al. 2000), which showed that whereas the effects of a combination of anthropogenic and natural forcings on the climate system could explain the evolution of global mean temperatures over the twentieth century, natural factors failed to explain the warming observed over the second half of the century (Stott et al. 2006).

A potential criticism of many of these simulations is that they fail to include forcings that are potentially important, and therefore agreement between models and observations could be a fortuitous result of the cancellation of errors. Forcings that are potentially important on regional scales, but were not previously believed to be important globally and were therefore omitted from many simulations, include black carbon from fossil fuel burning, biomass burning, and land use changes.

This paper describes simulations of twentieth-, twenty-first-, and twenty-second-century temperature change made with the Hadley Centre Global Environmental Model version 1 (HadGEM1), which is a new coupled climate model (see section 2) that was used to simulate climate change with a number of different climate forcings, including black carbon and land use changes. We investigate how well the model simulates past temperature changes (section 3) and determine whether a significant anthropogenic influence on observed temperatures can be detected (section 4).

As part of this study, we compare modeled temperature changes aloft with a recent analysis of temperatures deduced from radiosonde observations stretching back to 1958 (section 5). We concentrate on radiosonde data because the majority of detection and attribution analyses of free-atmosphere temperature changes have used data from radiosondes. Since the beginning of the satellite era in 1979, radiosonde records and some records based on satellite data show a smaller warming aloft in the Tropics than at the surface, in contradiction to climate models, which show more warming aloft, although there is currently a large uncertainty in observational estimates of tropospheric temperature trends over this period (Thorne et al. 2005a; Santer et al.
2005). However, a recent reanalysis of the satellite data (Mears and Wentz 2005) and a comparison with models (Santer et al. 2005) indicates consistency between models and this new reanalysis. Here we wish to compare our model with observational estimates over the longer radiosonde period. Hence, we use the latest version of the Hadley Centre radiosonde temperature product (Thorne et al. 2005b). Recently, Sherwood et al. (2005) have highlighted problems in the raw radiosonde data that lead to a spurious cooling, which they argue will have been at best undercorrected to date under all dataset homogenization approaches. Although this has not been rigorously proven, it is likely that any residual bias in the observations considered here, particularly in the Tropics, will be toward excessive cooling.

Finally, we describe predictions of possible future temperature change using HadGEM1 (section 6). In addition to simulations of twenty-first-century climate change in which anthropogenic emissions are increased, a new experiment has been carried out in which anthropogenic forcings are held constant at 2100 levels during the twenty-second century. The aim is to determine the likely commitment to further warming that exists because of past increases in concentrations of greenhouse gases, aerosols, and other anthropogenic factors and emissions, regardless of future emissions changes in concentrations.

\section{Model description}

The standard atmospheric component of HadGEM1 utilizes a horizontal resolution of $1.25^{\circ}$ latitude $\times 1.875^{\circ}$ longitude, with 38 layers in the vertical extending to over $39 \mathrm{~km}$ in height. The oceanic component utilizes a latitude-longitude grid with a zonal resolution of $1^{\circ}$ and meridional resolution of $1^{\circ}$ between the poles and $30^{\circ} \mathrm{N}$, from which it increases smoothly to $1 / 3^{\circ}$ at the equator, giving $360 \times 216$ grid points in total, and 40 unevenly spaced levels in the vertical (a resolution of 10 $m$ near the surface).

HadGEM1 has at its center a new atmospheric nonhydrostatic dynamical core ["new dynamics" ("ND"); Davies et al. 2005], employing a semi-implicit, semiLagrangian time integration scheme. The atmospheric model, includes a fully interactive modeling of atmospheric aerosols, driven by surface and elevated emissions (from both natural and anthropogenic sources), including tropospheric chemical processes as well as physical removal processes, such as washout. The aerosol species represented are sulfate, black carbon, biomass smoke, and sea salt. (Mineral dust is not yet modeled.) Consequently, this model is able to much more fully represent the direct and indirect effects of 
TABLE 1. HadGEM1 transient simulations.

\begin{tabular}{lc}
\hline \hline & Run length \\
\hline Control & $>350 \mathrm{yr}$ \\
$1 \%$ per annum $\mathrm{yr}^{-1}$ increasing $\mathrm{CO}_{2}$ & $140 \mathrm{yr}$ \\
$2 \times \mathrm{CO} 2$ & $150 \mathrm{yr}$ \\
$4 \times \mathrm{CO} 2$ & $150 \mathrm{yr}$ \\
Historical anthropogenic (ANTHRO) & $144 \mathrm{yr}(1860-2004)$ \\
Historical all forcing (ALL) & $144 \mathrm{yr}(1860-2004)$ \\
SRES A1B & $100 \mathrm{yr}(2000-2100)$ \\
SRES A2 & $100 \mathrm{yr}(2000-2100)$ \\
A1B extension to 2200 & $100 \mathrm{yr}(2100-2200)$ \\
\hline
\end{tabular}

aerosols than was possible with the previous model, HadCM3. The ocean component, HadGOM1, is based on the Bryan-Cox code (Bryan 1969; Cox 1984) and the ocean component of HadCM3 (Gordon et al. 2000), but has a much more detailed bathymetry than does HadCM3, which allows for better resolution of islands and channels, and has a sophisticated treatment of sea ice, including the use of elastic-viscous-plastic ice dynamics to calculate ice velocities and a representation of ice ridging. Further details of the atmospheric component are given by Martin et al. (2006) and details of the ocean and sea ice model components are given by Johns et al. (2006).

A number of transient coupled model simulations have been made with HadGEM1 (summarized in Table 1) and forms a major part of the Hadley Centre's contribution to the IPCC Fourth Assessment process. They were initialized from a long control run of HadGEM1, which uses fixed 1860 forcing levels for greenhouse gases, ozone, sulfur, and other aerosol precursor emissions and land surface boundary conditions. The control run was initialized and spun up from an ocean state using climatological fields for September mean potential temperature and salinity (Levitus et al. 1998) at rest. Sea ice was initialized as described by McLaren et al. (2005, manuscript submitted to J. Geophys. Res.), and the atmosphere was from an analyzed state corresponding to 1 September 1978. Further details of the spinup procedure are given in Johns et al. (2006).

The HadGEM1 control run was initialized after 85-yr of coupled spinup, a shorter duration than is ideal (necessitated by the requirement to have transient simulations ready in time for the IPCC Fourth Assessment Report), but was sufficient enough to allow the faster components of the climate system to approach equilibrium. Two historical transient simulations of the 1860 2004 period were commenced at the same time as the control from the same start conditions at the end of the $85-\mathrm{yr}$ spinup period. The first of these, denoted ALL, contains anthropogenic forcings from greenhouse gases, ozone, aerosols, and land use changes as well as natural forcings from solar changes and volcanic eruptions. The second of these, denoted ANTHRO, contains all the anthropogenic forcings in ALL and omits the natural forcings. The incorporation of these forcings into the model is described in detail below.

Computing limitations meant that only a relatively small number of HadGEM1 simulations could be made in time for input into the IPCC Fourth Assessment Report, and it was not possible to make ensembles of transient simulations of past climate change with identical forcings but different initial conditions. Such ensembles increase the strength of the forced signal relative to climate noise generated by internal variability. Nevertheless, we carry out a detection and attribution analysis in section 4 , and we intend to carry out further ANTHRO and ALL simulations in order to better quantify the initial attribution estimates made in this paper.

Two HadGEM1 predictions of possible future climate change to 2100 were made following the Special Report on Emissions Scenarios (SRES; Nakicenovic and Swart (2000). One prediction follows the A1B scenario and is a continuation of the ANTHRO simulation and another prediction follows the A2 scenario and is initialized at 1 December 1999 from the ANTHRO simulation. Also, a continuation of the A1B simulation was made in which forcing was stabilized at 2100 levels during the twenty-second century by fixing the annual concentration of long-lived greenhouse gases and the emissions of short-lived aerosol species, although the seasonally varying quantities had their seasonal cycles preserved.

Further idealized transient simulations were made in time for inclusion in the IPCC Fourth Assessment Report, including an idealized $1 \% \mathrm{yr}^{-1}$ increase in carbon dioxde for $80 \mathrm{yr}$ starting from the control carbon dioxide level; this is described by Lowe et al. (2005, manuscript submitted to J. Climate, hereafter LOW05). At the time of carbon dioxide doubling the global mean temperature response (averaged over a 20 -yr period) is $1.8 \mathrm{~K}$, which is slightly lower than the equivalent value for HadCM3 of $2.0 \mathrm{~K}$. The effective climate sensitivity (Senior and Mitchell 2000) calculated at the time of $\mathrm{CO}_{2}$ doubling is $2.8 \mathrm{~K}$, which is slightly lower than the equivalent value for HadCM3 of $3.1 \mathrm{~K}$ (see Johns et al. 2006 for more details). The equilibrium sensitivity of the atmospheric component of HadGEM1 coupled to a slab ocean is $4.4 \mathrm{~K}$ and is higher than the equilibrium sensitivity of HadCM3 coupled to a slab ocean, which is $3.3 \mathrm{~K}$. The higher sensitivity in the slab ocean version of HadGEM1 compared to the effective climate sensitivity of HadGEM1 is related to differences in sea ice 
feedbacks; the slab model environment is not deemed an appropriate environment for analyzing sea ice feedbacks in HadGEM1 (Johns et al. 2006).

We now provide a description of how the various forcings were included in the model. Most of the anthropogenic forcings are described in detail in other papers, so we summarize these only briefly here referring the reader to the relevant literature. However, the natural forcings are not described in detail elsewhere so we take this opportunity to provide a more in-depth description of how solar and volcanic forcings were included in the model.

\section{a. Greenhouse gases}

The well-mixed greenhouse gases that are included are $\mathrm{CO}_{2}, \mathrm{CH}_{4}, \mathrm{~N}_{2} \mathrm{O}$, and a subset of the halocarbon species considered to be the next largest contributors to anthropogenic forcing, namely, $\mathrm{CFCl}_{3}$ (CFC-11), $\mathrm{CF}_{2} \mathrm{Cl}_{2}$ (CFC-12), $\mathrm{CF}_{2} \mathrm{ClCFCl}_{2}$ (CFC-113), and $\mathrm{CHF}_{2} \mathrm{Cl}$ (HCFC-22). The concentrations chosen to represent concentrations up to 2000 are those tabulated on the Ensemble-based Prediction of Climate Change and their Impacts (ENSEMBLES) research theme (RT) 2A Web site (available online at http://www.cnrm.meteo.fr/ensembles/ ), and concentrations from 2000 to 2004 in the ALL and ANTHRO past transient simulations are assumed to follow those specified by the SRES A1B scenario (Nakicenovic and Swart 2000). Concentrations in the two predictions follow the SRES A1B and A2 scenarios.

\section{b. Ozone}

Ozone concentrations from 1870 to 1990 are taken from the Stratospheric Processes and their Role in Climate (SPARC) dataset (Randel and Wu 1999; Randel et al. 2003; Kiehl et al. 1999). Estimates of stratospheric ozone after 1990 were made by assuming a linear relationship between effective equivalent stratospheric chlorine (EESC) and ozone changes (Daniel et al. 1995). The burdens of ozone-depleting halogens, which contribute to EESC, were predicted as in Montzka et al. (1999). Three-dimensional fields of monthly mean tropospheric ozone were computed for future conditions using the offline Met Office Lagrangian model of tropospheric chemistry (STOCHEM) chemistry transport model (Collins et al. 1997) coupled to the atmospheric component of HadGEM1, with sea ice and sea surface temperatures taken from earlier HadCM3 results for the appropriate time horizon. This model used time-dependent emissions appropriate to the scenario from Nakicenovic and Swart (2000); concentrations were interpolated from model simulations for 1990 , 2030, 2060, and 2100.

\section{c. Aerosols}

The interactive schemes implemented in HadGEM1 to deal with sulfate, black carbon, and biomass aerosols are described in detail in Martin et al. (2006). Natural emissions of sulfur from dimethylsulfide (DMS) and volcanoes are taken to be time invariant and were based on Kettle et al. (1999), Jones and Roberts (2004), and Andres and Kasgnoc (1998). Pre-2000 anthropogenic emissions of sulfur used data provided by S. J. Smith (Pacific Northwestern National Laboratory, 2004, personal communication). In the ALL and ANTHRO past transient simulations, emissions between 2000 and 2004 are assumed to follow those specified by the SRES A1B scenario (Nakicenovic and Swart 2000) and the two predictions follow the SRES A1B and A2 scenarios. Past and future fossil fuel black carbon and biomass smoke emissions were based on datasets provided by T. Nozawa (National Institute for Environmental Studies 2004, personal communication).

\section{d. Land use changes}

Land surface processes are modeled using the second Met Office Surface Exchange Scheme (MOSES-II; Cox et al. 1999); further details are given in Martin et al. (2006). Land use changes during the course of the transient simulations up to 2000 are incorporated following Goldewijk (2001). Post-2000 land use changes were taken from the Integrated Model to Assess the Global Environment (IMAGE) model in its derivation of the SRES scenarios (Alcamo et al. 1998).

\section{e. Solar forcing}

Direct observations of total solar irradiance (TSI) from satellites are available only since 1979. Different methods have been used to reconstruct TSI from before the satellite era, most of which use different proxy measurements of solar activity. We use the Solanki and Krivova (2003, hereafter SK) reconstruction of TSI, which was recommended to us by Gray et al. (2005) following an independent consultation exercise. There are other possible and plausible reconstructions of TSI (e.g., Hoyt and Schatten 1993; Lean et al. 1995a; Lean 2000; Lean et al. 2002), which have wide ranges of TSI evolution, including one that has no long-term variation at all. The SK reconstruction comprises a solar cycle and long-term variation component. Sun spot numbers (SSNs) were fitted to satellite observations of TSI. The 11-yr cycle in TSI can then be reconstructed into the past by scaling SSN. The amplitudes of the cycles in SSN were used to create the temporal evolution of the secular changes in TSI. The magnitude of the secular change is scaled by the estimated change in solar irra- 

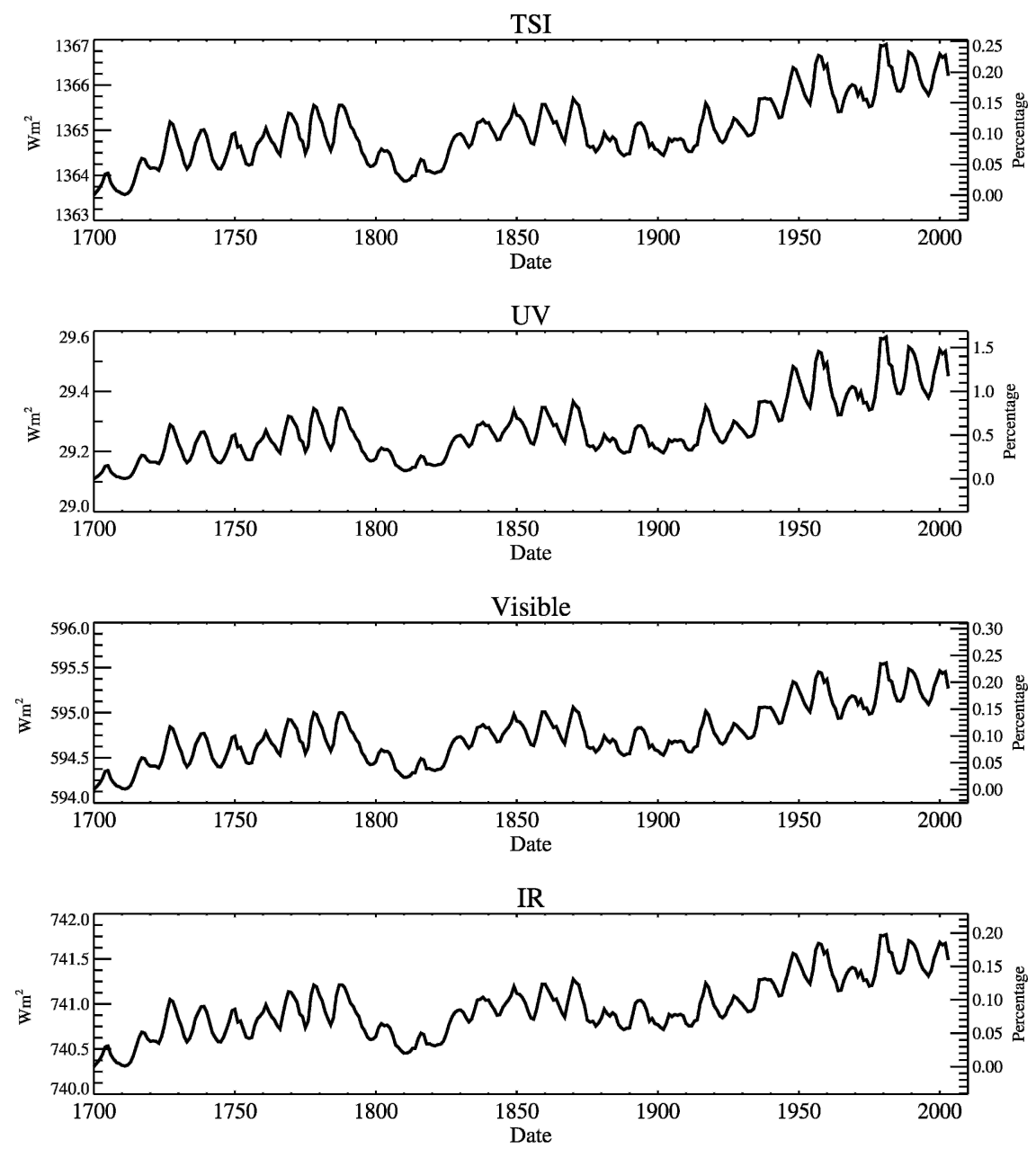

FIG. 1. Solar irradiance changes from Solanki and Krivova (2003). (top) Shown are TSI changes, offset for mean of 1700-2004 period to be $1365 \mathrm{~W} \mathrm{~m}^{-2}$. Also shown are variations in the TSI partitioned in HadGEM1's (upper middle) shortwave spectral UV (200-320 nm), (lower middle) visible (320-690 nm (two bands), and (bottom) IR (690-1190, 1190-2380, and 2380-10000 nm).

diance between the Maunder minimum (MM) (Eddy 1976) and present data solar cycle minimum, which we took to be $2.15 \mathrm{~W} \mathrm{~m}^{-2}$ (as recommended by Gray et al. 2005), and within the plausible range of $2-4 \mathrm{~W} \mathrm{~m}^{-2}$ of Solanki and Krivova (2003). By obtaining independent advice, we hope to reduce the risk that our choice of TSI is influenced by its chance of causing the climate change we are investigating.

The solar cycle and secular reconstructions were combined with the Frohlich and Lean (1998) satellite reconstruction to create the overall TSI variations. The resulting TSI variations (Fig. 1) are quite similar to the Lean et al. (1995a) reconstructions used previously in HadCM3 simulations of twentieth-century climate (e.g., Stott et al. 2000).

Annual mean TSI values are calculated from the SK daily values as anomalies with respect to the 1700-2003 period, so that the mean is $1365 \mathrm{~W} \mathrm{~m}^{-2}$, the value of the solar constant in the control integration (Fig. 1, top panel). This results in a small, positive jump in TSI values at the start of the ALL simulation in 1860 of $0.57 \mathrm{~W} \mathrm{~m}^{-2}$. Incoming solar shortwave radiation is partitioned across six spectral bands covering the range of 0.2-10 $\mu \mathrm{m}$ (see Martin et al. 2006; Johns et al. 2006, and references therein for more details about the HadGEM1 radiation scheme). In reality, the spectral distribution of irradiance is estimated to change from the MM to present and from solar minima to solar maxima (Lean et al. 1995b). To take this into account a fit was made to the estimated spectral distribution change of Lean et al. (1995b), and the fraction of irradiance in each of the model shortwave bands varied as 


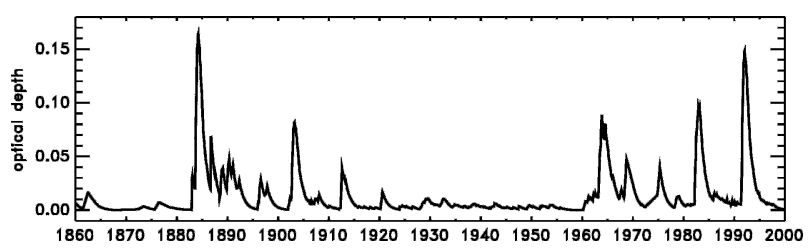

FIG. 2. Monthly global mean stratospheric volcanic aerosol optical depth, for period 1860-2000, from Sato et al. (2002).

the TSI varies (Fig. 1, second, third, and fourth panels). Over the twentieth century the TSI increases by about $0.1 \%$, but the proportion in the shortest wavelength band covering the UV $(0.2-0.32 \mu \mathrm{m})$ increases by $0.6 \%$, while the other bands increase by less than $0.1 \%$. The Rayleigh scattering and ozone absorption properties are also amended to compensate for the change in the distribution of the radiation within each spectral band, but the ozone concentrations do not change interactively with the UV changes. The method of applying the solar irradiance changes is the same as that used in HadCM3 (Tett et al. 2002; Stott et al. 2000).

Over the 1850-2004 period the TSI increases by $1.5 \mathrm{~W} \mathrm{~m}^{-2}$. Most of that increase is in the early part of the twentieth century, with the mean TSI having a small secular change over the last $30 \mathrm{yr}$.

\section{f. Volcanic forcing}

The main climatic influence of volcanoes results from injection by large volcanic eruptions of sulfur dioxide into the stratosphere and conversion to sulfate aerosols (Robock 2000). We use the reconstruction of volcanic stratospheric aerosol optical depth from Sato et al.
(1993) (extended to 2000; Sato et al. 2002), based on various optical opacity measurements (Fig. 2; see information online at http://www.giss.nasa.gov/data/strataer/).

The small volcanic aerosol present in 1999 was allowed to decay with a lifetime of $1 \mathrm{yr}$ to obtain values up to 2004. Other reconstructions of volcanic forcing proxies are available, but we choose the Sato et al. (2002) series, which (like the Stothers reconstructions) is based on observations of the changing atmosphere optical properties and would directly influence the climate, rather than other series based on ice core data and model output, which surmise the impact on climate. The values given are for monthly mean optical depths for 24 latitudinal zones and four levels in the stratosphere (15-20, 20-25, 25-30, and 30-35 km). We average the zones over four equal-area latitudinal zones $\left(90^{\circ}-30^{\circ} \mathrm{N}, 30^{\circ} \mathrm{N}-0^{\circ}, 0^{\circ}-30^{\circ} \mathrm{S}, 30^{\circ}-90^{\circ} \mathrm{S}\right)$ and over the four levels in order to minimize the effect of variable accuracy in the optical depth measurements of the Sato et al. (2002) dataset resulting from the differing observation methods and changing data coverage (Fig. 3).

The monthly mean optical depths were converted into a sulfate aerosol mass mixing ratio and were spread evenly across the model levels above the tropopause. (Aerosol mass is calculated as $1.917 \times 10^{8} \mathrm{~kg} \mathrm{~m}^{-2}$ per 0.0001 optical depth.) The time series (Fig. 2) is dominated by four explosive eruptions: Krakatoa (1883), Mt. Agung (1963), El Chichón (1982), and Mt. Pinatubo (1991).

The radiative effect of stratospheric aerosols is modeled by scattering and absorbing incoming shortwave radiation from the sun across spectral bands covering
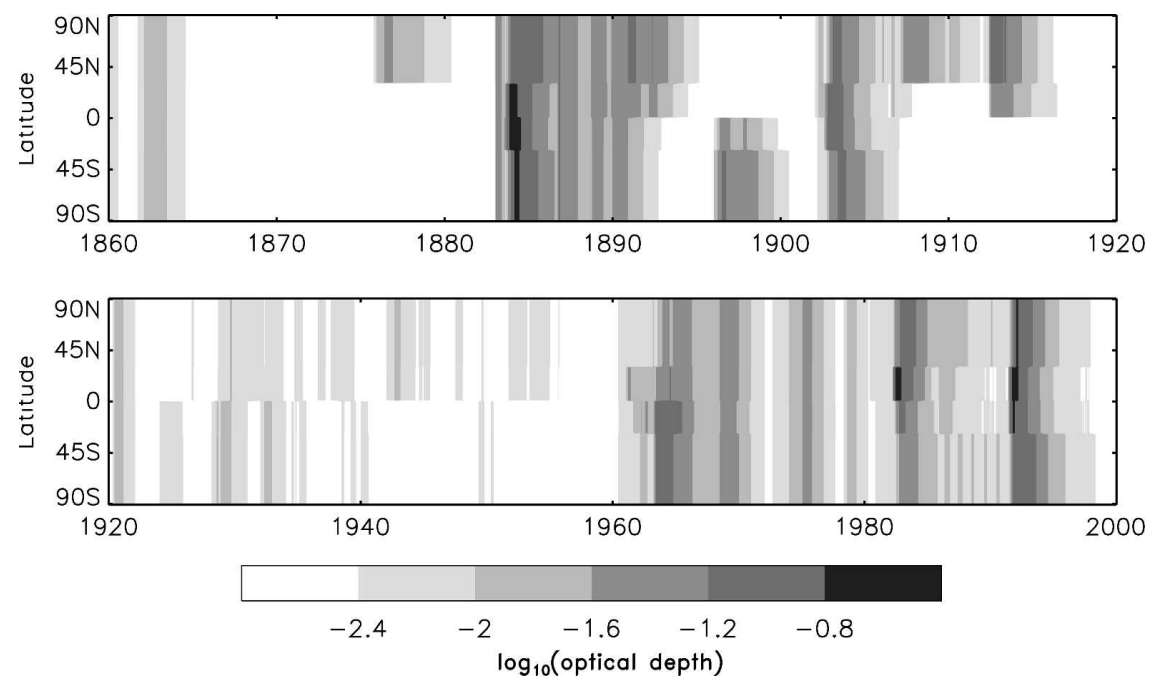

FIG. 3. Monthly zonally averaged stratospheric volcanic aerosol optical depth, for the period 1860-2000. Optical depth data from Sato et al. (2002) zonally averaged into four equal-area latitude zones. 
the range of $0.2-10 \mu \mathrm{m}$, assuming a constant aerosol size distribution and a 3-1 composition of sulfuric acid and water by weight. Most of the scattering is at the shorter wavelengths and most of the absorption is at the longer wavelengths, including the near-IR. Similarly, the aerosol absorbs longwave radiation that is reemitted by the surface and troposphere (see Martin et al. 2006; Johns et al. 2006, and references therein for details of the HadGEM1 radiation scheme and how aerosols are modeled). The stratospheric aerosol is prescribed and its chemistry, size distribution, and spatial distribution do not evolve interactively.

\section{Simulation of past near-surface temperature changes}

Annual mean global mean temperatures as simulated by HadGEM1 from 1870 to 2004 are compared with the instrumental record of near-surface temperature based on the Hadley Centre/Climate Research Unit Temperature version 2 with improved variances (HadCRUT2v) dataset (a blended combination of land-based measurements and sea surface temperatures) for the ANTHRO (Fig. 4a) and ALL (Fig. 4b) simulations. The observed trend over the last three decades is captured by both simulations, but the inclusion of natural forcings appears to improve the simulation of temperature changes earlier in the century. Taking the difference between the two simulations (Fig. 4c) provides an estimate of the effects of natural forcings on temperature. In this case, the recent observed warming is not captured. A comparison of observed and simulated decadally averaged temperatures (Fig. 5) shows that the simulation including both anthropogenic and natural forcings warms in the first half of the twentieth century, and cools and then warms during the last three decades of the century. Exclusion of anthropogenic forcings causes the simulation to be inconsistent during the 1980s and 1990s. These results are in line with simulations of other coupled models, which are only able to capture warming trends observed since the 1970s when anthropogenic forcings are included (Broccoli et al. 2003; Meehl et al. 2004; Stott et al. 2006).

The spatial patterns of near-surface temperature trends are shown in Fig. 6 for three 30-yr periods during the twentieth century. The ALL simulation has more warming in the 1910-39 period than the ANTHRO simulation, but neither simulation captures the widespread warming seen in the North Atlantic, a feature that could be associated with unforced multi-decadalscale variability of the thermohaline circulation (Knight et al. 2005). The overall cooling trend observed between 1940 and 1969 is also seen in the model simula-
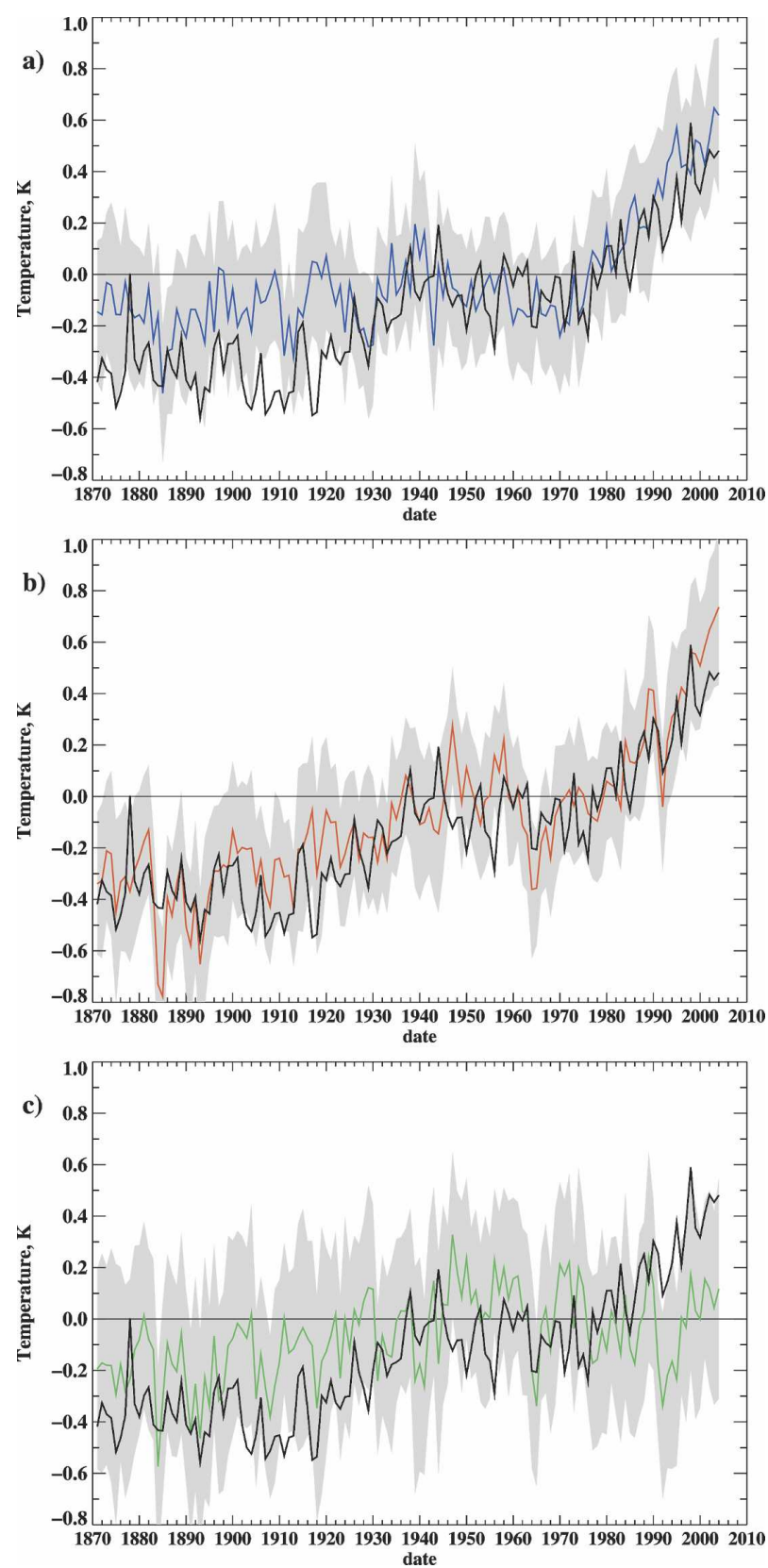

FIG. 4. Global mean annual mean near-surface $(1.5 \mathrm{~m})$ temperatures for (a) ANTHRO, (b) ALL, and (c) NATURAL, where NATURAL is the difference between ALL and ANTHRO. Temperatures compared with observations of near-surface temperature. Temperatures masked by observational coverage, calculated as anomalies with respect to the 1961-90 mean and offset so that the mean of the entire period is 0 . Uncertainties are calculated from overlapping segments of annual mean temperatures from the HadGEM1 control processed in the same way as the simulations and overlapping by $5 \mathrm{yr}$. The shaded regions represent \pm 2 std devs calculated from this uncertainty. Because NATURAL is calculated as the difference, ALL-ANTHRO, the shaded region in (c) is scaled by $\sqrt{ } 2$ to allow for the larger variance. 


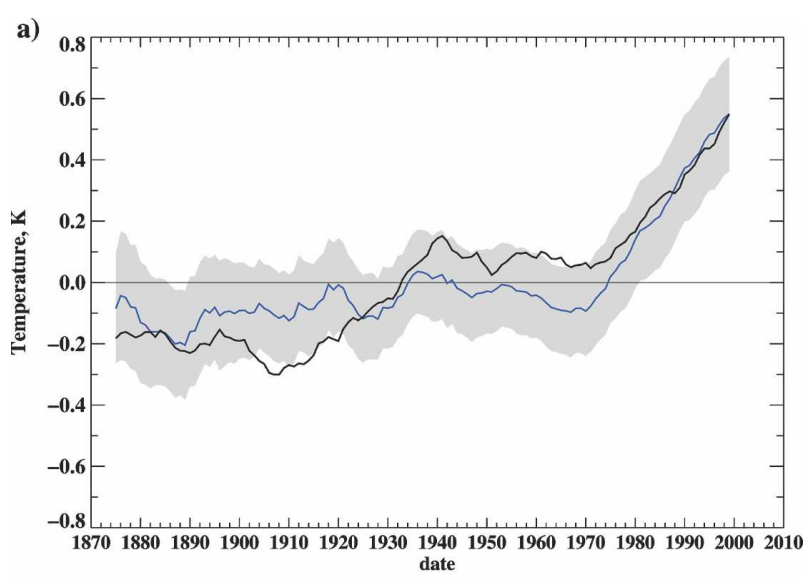

b)
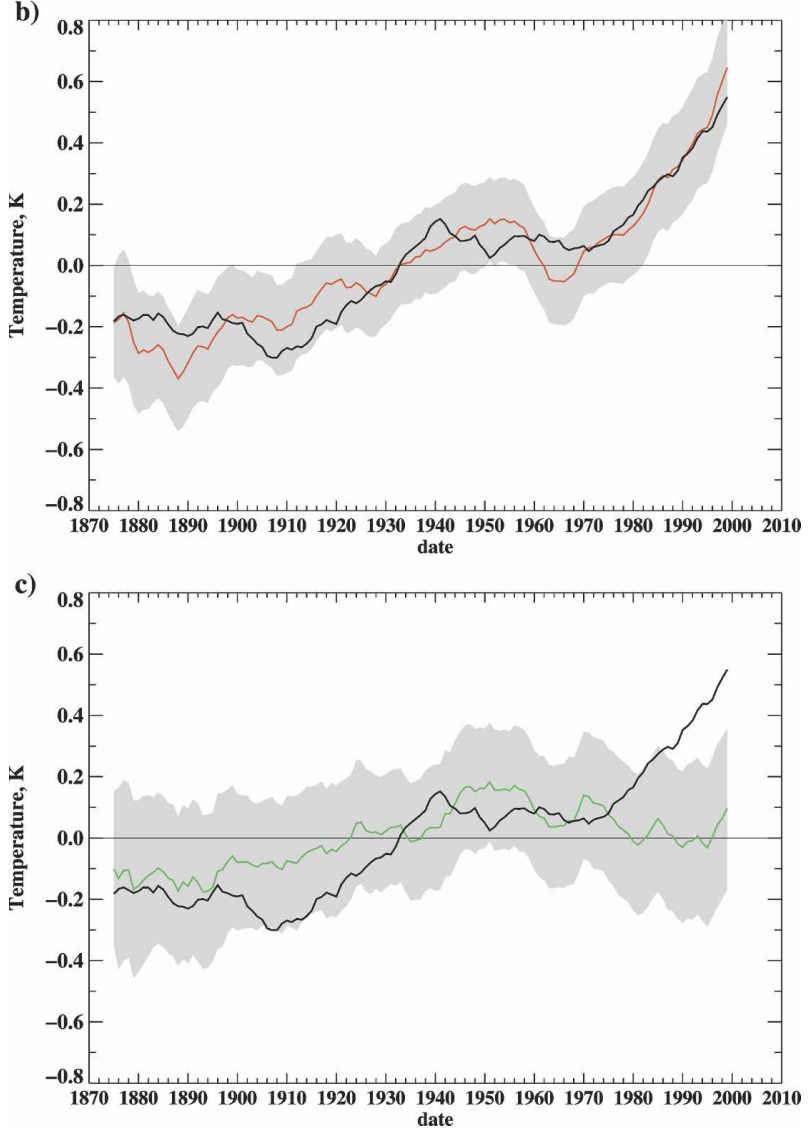

FIG. 5. The 10-yr running means of global mean near-surface (1.5 m) temperatures. Shown are (a) ANTHRO, (b) ALL, (c) NATURAL (difference between ALL and ANTHRO), and the observations. The plots are offset such that the mean of the entire period is 0 . Uncertainties are calculated from 50 segments of annual mean temperatures from the HadGEM1 control processed in the same way as the simulations and overlapping by $5 \mathrm{yr}$. The shaded regions represent \pm 2 std devs calculated from this uncertainty. Because NATURAL is calculated as the difference, ALLANTHRO, the outer shaded region in (c), is scaled by $\sqrt{ } 2$ to allow for the larger variance. tions. Both ANTHRO and ALL simulations, like the ob servations, show a widespread warming trend since 1970.

A more detailed examination of the simulated largescale features of the surface temperature response is given in Fig. 7. This shows that the ALL simulation is a generally good simulation of the evolution of temperature changes when separated into the components over land and ocean, over the Northern and Southern Hemispheres, and over mid- to high latitudes and subtropical latitudes. The land-ocean, Northern-Southern Hemisphere, and midlatitude-low latitude differences are basic indices of the large-scale spatial patterns of temperature change that have been used in previous studies (e.g., Karoly and Braganza 2001). The ALL simulation captures some of the main features seen in these indices, including the observed late-twentieth-century decrease and then increase in the temperature difference between the Northern and Southern Hemispheres (Fig. 7 middle row right-hand panel). It is likely that this characteristic feature is a fingerprint of the interhemispheric effects of aerosols on near-surface temperature change (Santer et al. 1996; Stott et al. 2006).

HadGEM1 also captures many features of the variability and trends in near-surface temperatures observed on subcontinental land areas (Fig. 8). This was also the case for simulations of HadCM3, which included both anthropogenic and natural forcings (see Fig. 6 of The International Ad Hoc Detection and Attribution Group 2005). Like HadCM3, the HadGEM1 ALL simulation shows steady warming in South Africa, southern South America, and South Asia. Some features of the North American temperature changes appear to be better captured by HadGEM1 than HadCM3, notably the early century warming in western North America, although HadGEM1 fails to capture the early century warming in northern Europe. However, particularly in this latter region, variability is high, and it is therefore difficult to draw conclusions about forced changes from a single model simulation and a single realization of real-world temperatures. Accelerating warming is seen in the Sahara region in both HadCM3 and HadGEM1. In mid-Asia, the HadGEM1 ALL simulation shows a cooling in the middle of the century, a feature that was also seen in HadCM3 but not in the observations. Stott (2003) reported that HadCM3 appeared to overestimate sulfate aerosol cooling in Asia, which he speculated could have been a result of real-world warming from black carbon counteracting some cooling from sulfates. However, the inclusion of black carbon in the HadGEM1 simulations does not appear to make a large difference to simulations of Asian temperatures, where the effects of black 

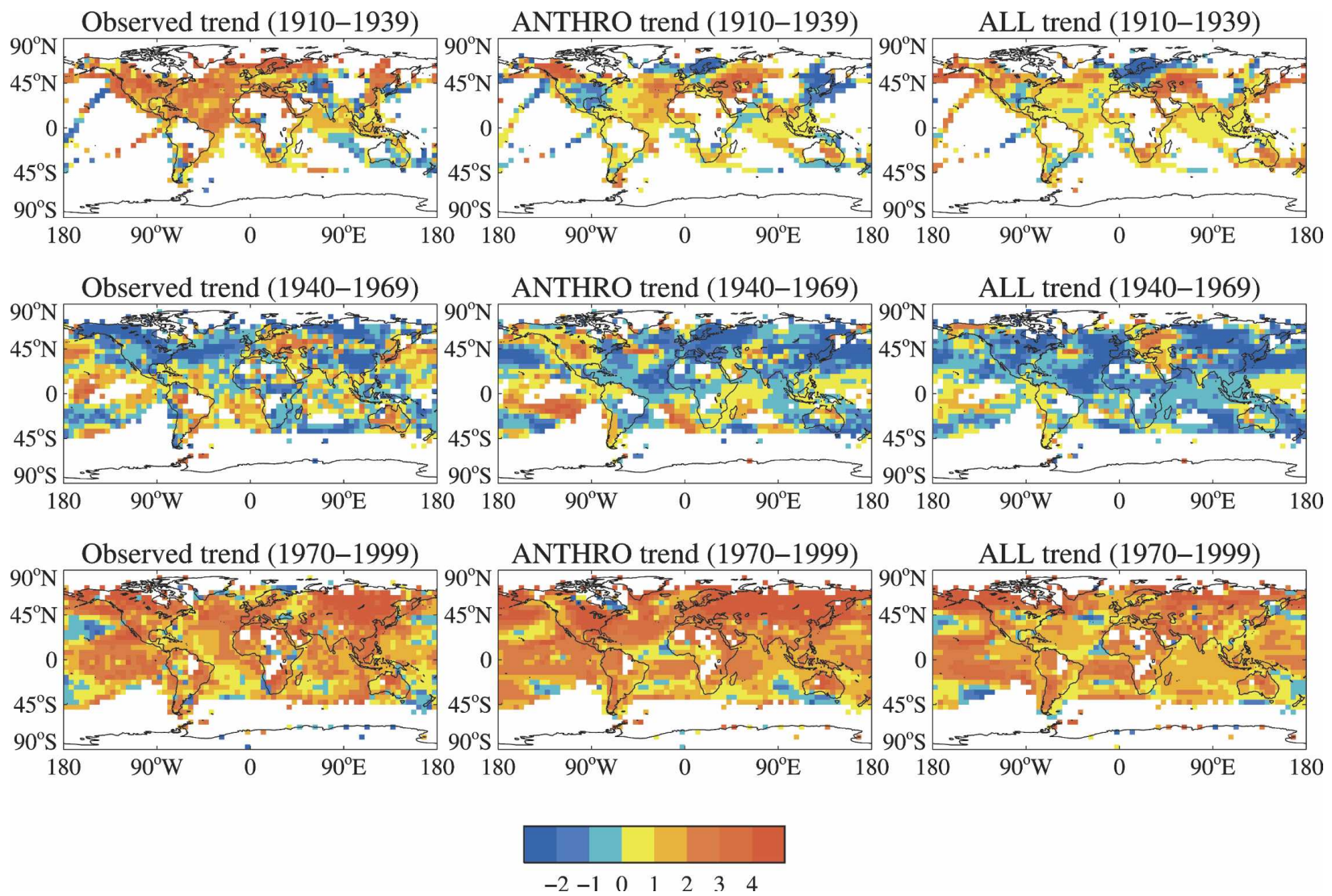

FIG. 6. Patterns of near-surface temperature trends $\left(\mathrm{K}\right.$ century $\left.{ }^{-1}\right)$ for three 30-yr periods $(1910-39,1940-69$, and 1970-99) for (left) OBSERVATIONS, (middle) ANTHRO, and (right) ALL.

carbon might be expected to be greatest (Roberts and Jones 2004).

\section{Detection and attribution of past near-surface temperature change}

In this section we investigate whether a significant anthropogenic influence on near-surface temperature changes is detected by applying an optimal detection analysis to the HadGEM1 simulations. Only a single simulation is available for each of the two scenarios, and we therefore expect lower signal-to-noise ratios for the modeled temperature response to anthropogenic and natural forcings than if we had the mean of a fourmember ensemble, as was the case for previous analyses using HadCM3 data. However, we now carry out the analysis for data up to 2004, providing an update on previous analyses that were for the 100 -yr period to 1999.

We assess the model's representation of natural variability by comparing the power spectra of HadCRUT2v global annual mean near-surface temperatures with those simulated by HadGEM1 (Fig. 9). The HadGEM1
ALL simulation appears to capture observed variability over the full range of time scales considered. Combined with the ability of the model to simulate the observed trends in global mean temperature (Fig. 5), this indicates that the model has an adequate representation of internal global mean variability, a key requirement for a detection analysis. It is interesting to note that the ANTHRO simulation has less variability on long (greater than century) time scales than either of the observations or ALL simulation (Fig. 9), consistent with some forced natural low-frequency multicentennial-scale variability.

A standard optimal detection analysis, similar to those used in previous studies (Allen and Stott 2003; Stott et al. 2003), is applied to the HadGEM1 simulations described earlier. Decadal means are calculated and projected onto spherical harmonics at T4 truncation. Ten spatial patterns over the 100 -yr period from 1 December 1904 to 30 November 2004 are projected onto the ordered eigenvectors calculated from the HadGEM1 control. Realizations of model noise are taken from a HadCM3 control simulation (Johns et al. 2003) for use in significance testing and uncertainty 

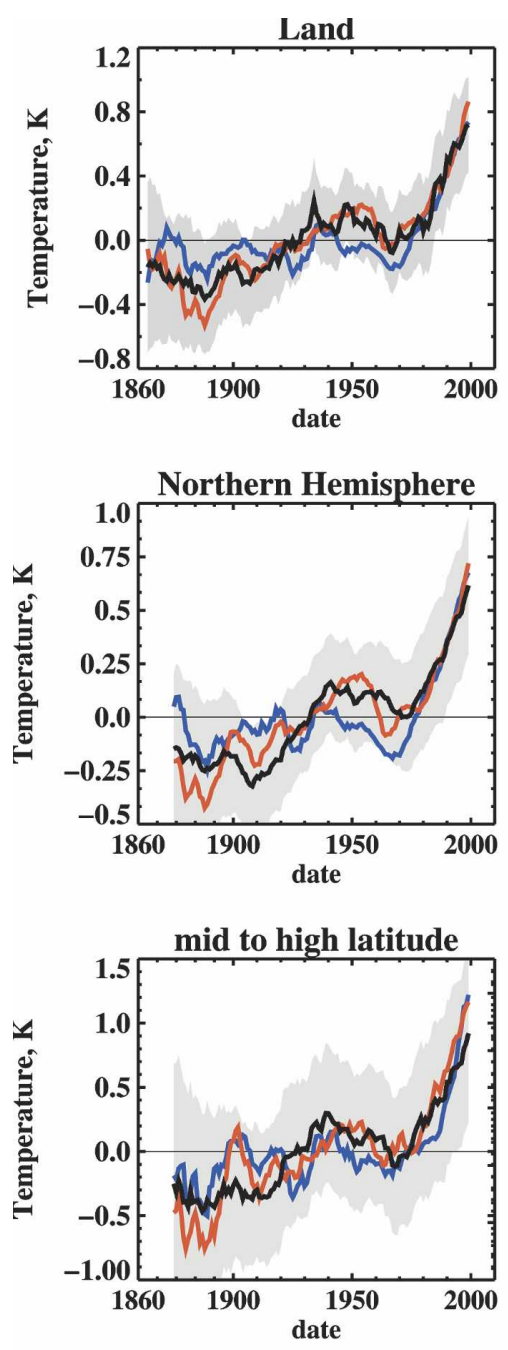

ANTHRO
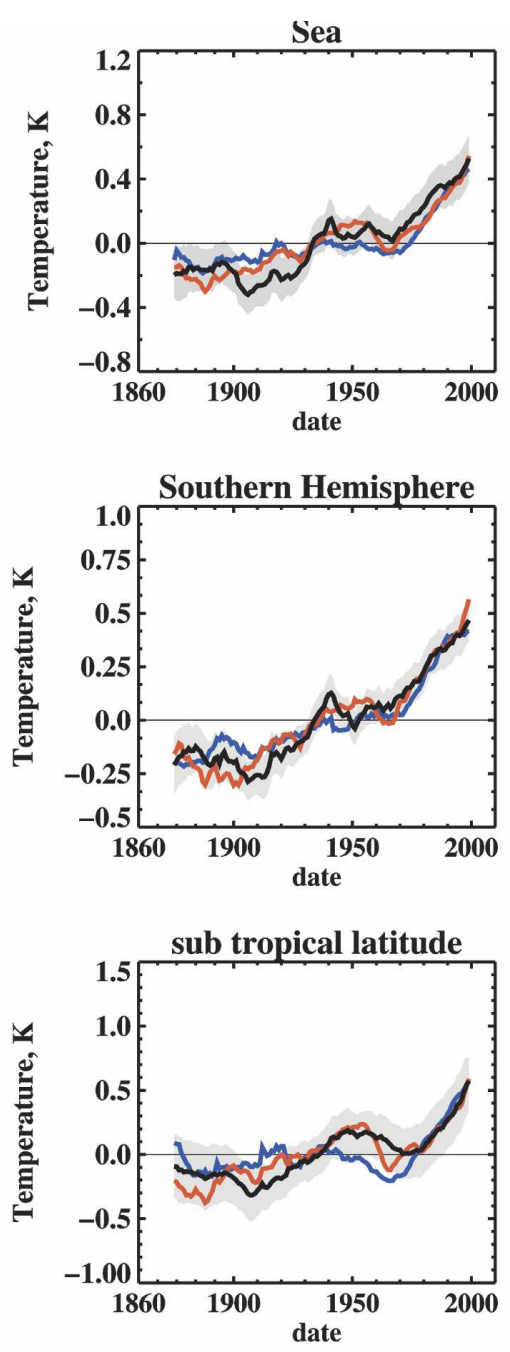

ALL
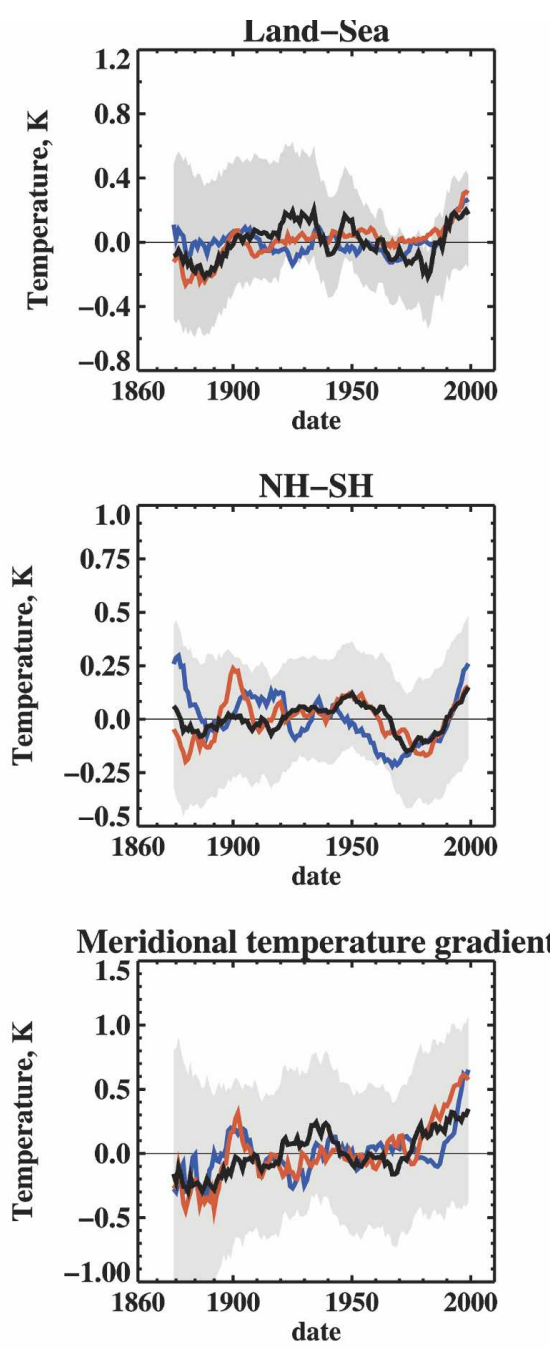

Observations

FIG. 7. 10-yr running mean 1.5-m temperatures for land, sea, land-sea, Northern Hemisphere, Southern Hemisphere, NH-SH, NH midlatitudes $\left(52.5^{\circ}-67.5^{\circ} \mathrm{N}\right)$, NH subtropical $\left(22.5^{\circ}-37.5^{\circ} \mathrm{N}\right)$ latitudes, and meridional temperature gradient (difference between $\mathrm{NH}$ midlatitudes and NH subtropical latitude bands). Plots offset such that the mean of the entire period is 0 . Uncertainties calculated as described in earlier figures. For clarity, model uncertainty is displayed around observations.

analysis. (We do this because the HadGEM1 control is not long enough.)

The individual signals of ALL and ANTHRO are detected separately (Table 2, first two rows; Fig. 10) with amplitudes consistent with unity, indicating that we have identified in the observations the presence of the expected response to anthropogenic forcing (as estimated by HadGEM1) and that the model's response to anthropogenic and natural forcings is consistent with that observed. However, we find that it is not possible to detect the response to anthropogenic or natural forcings separately when the ALL and ANTHRO simulations are combined in a single analysis (Table 2, third row).
The observed trend over the last $100 \mathrm{yr}$ (1904-2004) of $0.59 \mathrm{~K}$ century ${ }^{-1}$ (where the uncertainty of the underlying forced trend is calculated to be $0.43-0.75 \mathrm{~K}$ century $^{-1}$ and the $5 \%-95 \%$ are calculated from the HadGEM1 control) is consistent with scaled trends calculated from ANTHRO (0.38-0.73 K century ${ }^{-1}$; Fig. 11, blue bar, left-hand panel) and from ALL (0.42$0.79 \mathrm{~K}$ century $^{-1}$; Fig. 11, red bar, left-hand panel). (Note that these trends are calculated from decadal mean data, projected onto T4 spherical harmonics and onto a truncated set of eigenvectors, so they will be slightly different than when calculated with different methods.)

We tested the sensitivity to details of our use of the 

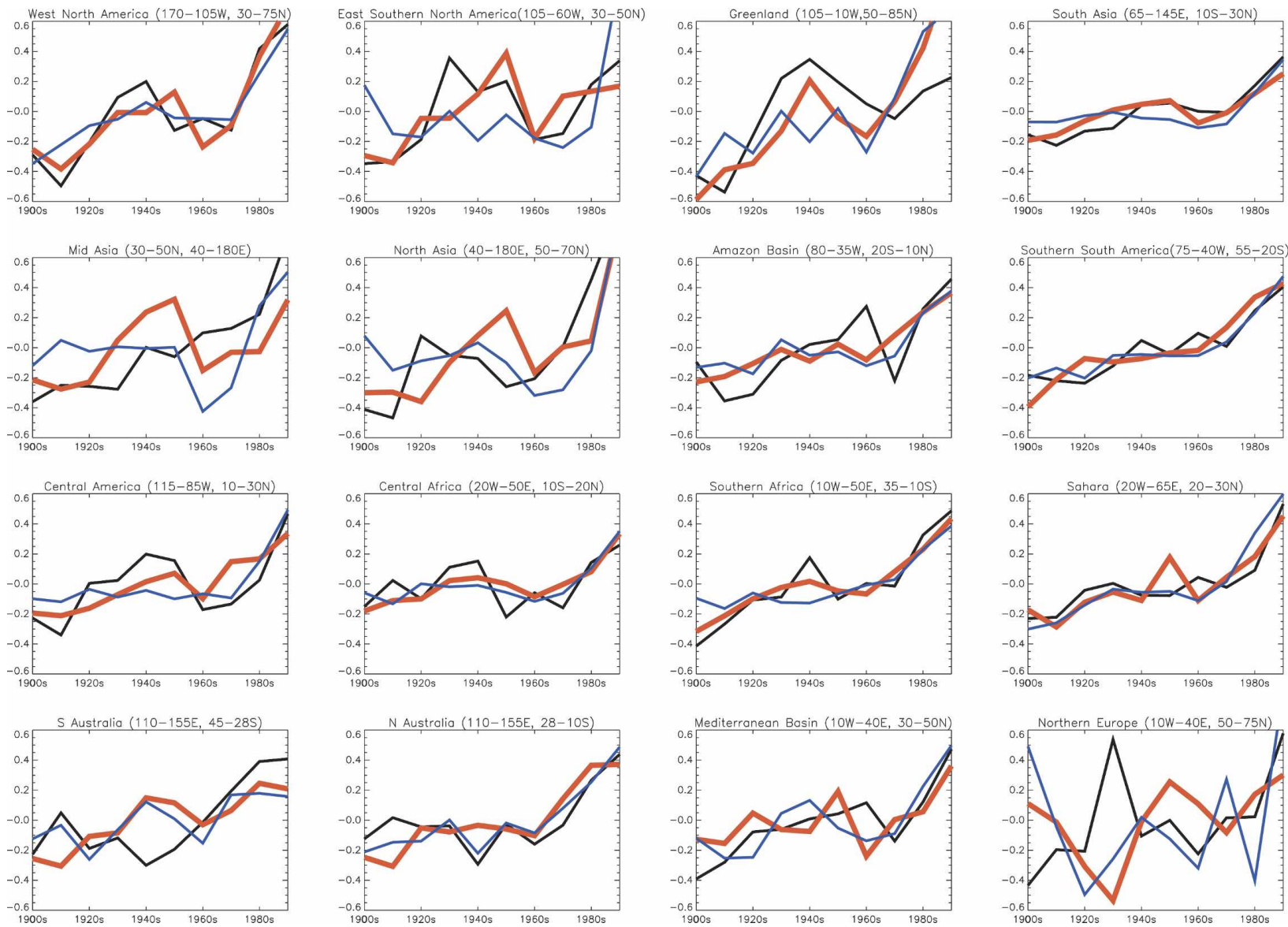

FIG. 8. Observed (black lines) and simulated (colored lines) decadal mean temperature changes in 16 subcontinental-scale land regions of the globe. Temperatures from the ALL simulation (red lines) and from the ANTHRO simulation (blue lines) are shown. The geographical domains of the regions are defined in Table 1 of Stott (2003).

control run (in which $390 \mathrm{yr}$ of a HadGEM1 control run was used for optimizing and a 400-yr segment of the HadCM3 control was used for hypothesis testing) by repeating the analysis using the HadCM3 control only, employing a 1500-yr segment for optimizing and another 1500-yr segment for hypothesis testing. We find slightly larger amplitudes (Table 2) using the HadCM3 control only.

The analysis was repeated for a succession of 50-yr periods starting at 10-yr intervals from 1904 to 1954. Here too there was no detection of the natural and anthropogenic components in a two-way ANTHROALL analysis. When analyzed separately, the ANTHRO signal is detected in the latter part of the century and ALL is detected both early and late in the century (Fig. 10).

In section 3 we showed that HadGEM1, like HadCM3, reproduces many features of observed change at global and large continental and subcontinen- tal scales, which is compelling evidence for a human influence on global and regional climates (The International Ad Hoc Detection and Attribution Group 2005). Taken together with the detection results presented in this section, these results indicate that black carbon and land use changes are relatively unimportant, compared to greenhouse gases and sulfate aerosols, and their omission from older model simulations does not invalidate the conclusion that the most recent warming is caused by anthropogenic factors. However, agreement between observed and modeled global mean temperature changes could be fortuitous to some extent with the possibility for a different cancellation of errors in HadGEM1 (with the extra forcings) than in HadCM3. Ensembles of HadGEM1 simulations will enable us to better quantify the contributions from anthropogenic and natural factors to twentieth-century temperature change and investigate further the role of black carbon and land use changes. 


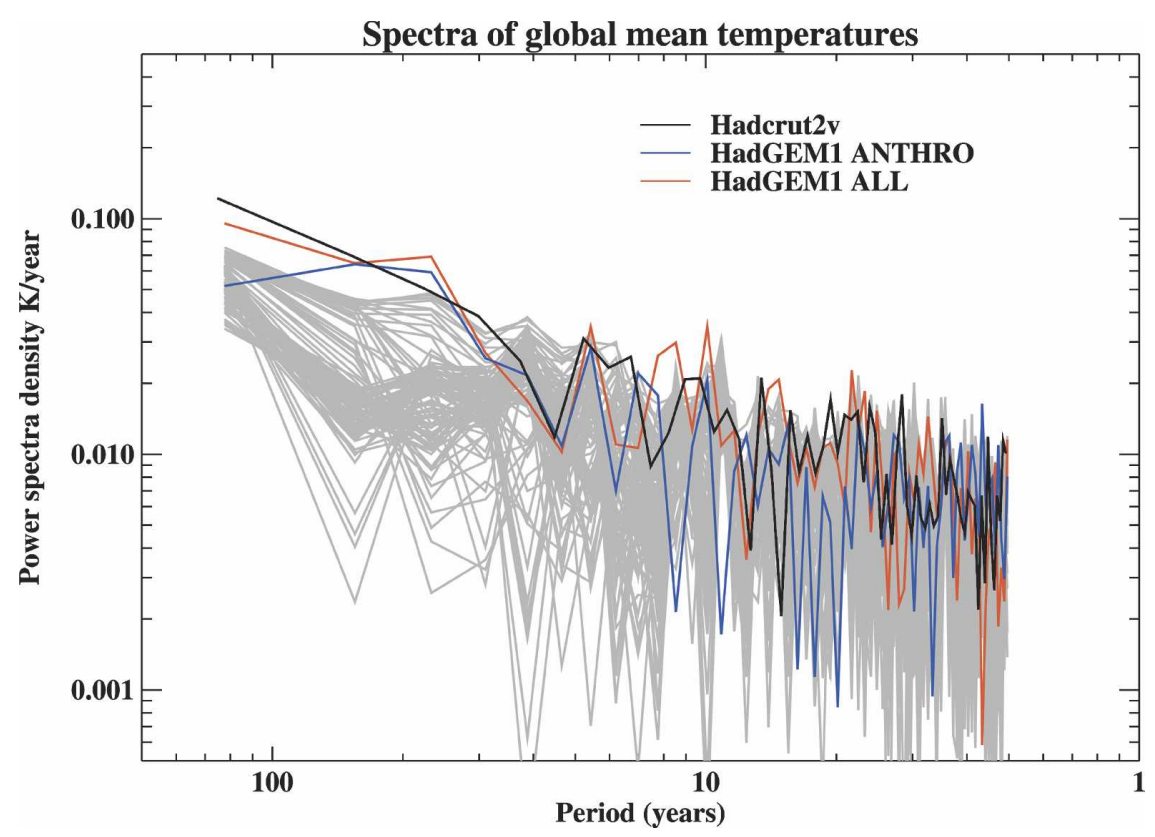

FIG. 9. Power spectra of HadGEM1 and HadCRUT2v global annual mean near-surface temperatures. Light gray lines are spectra of 100 segments of HadGEM1 that control overlapping by $5 \mathrm{yr}$.

\section{A comparison of HadGEM1 with HadAT2 radiosonde temperatures}

In this section we make a comparison of HadGEM1 simulations of temperature change through the depth of the atmosphere with radiosonde observations made from 1958 to present. We use the latest version of the Hadley Centre's radiosonde temperature product (HadAT2; Thorne et al. 2005b). It is available on nine standard reporting levels from 850 to $30 \mathrm{hPa}$ on a seasonal resolution from 1958 to 2002. Station series have been homogenized through a neighbor-based time series comparison. Homogenized station series have been gridded onto a $5^{\circ}$ latitude $\times 10^{\circ}$ longitude grid. Coverage is incomplete and varies throughout the time series. Coverage is particularly poor over the oceans and high southern latitudes, and above $100 \mathrm{hPa}$. It is also much poorer than that for HadCRUT2v (Parker et al. 2004).
We use HadCRUT2v subsampled to the time-varying HadAT2 500-hPa field to provide a surface time series. For HadGEM1 transient ALL and ANTHRO runs the time-varying observational mask is applied to the 195899 data.

To assess uncertainty in these model predictions resulting from natural variability alone, 10 -yr-overlapping chunks of the control are taken and the time-varying observational mask is applied, which yields 30 estimates of an unforced time series. Thorne et al. (2005b) discuss observational errors, but because these are not directly equivalent to the model measures they are not included in this analysis.

We caution that this comparison is between a single model run rather than an ensemble and a single observational dataset rather than a range of available estimates. There is large uncertainty in observational trends aloft (Thorne et al. 2005a), so absolute trend

TABLE 2. Scaling factors for the period 1904-2004 for the method with HadGEM1 control for optimizing/creating eigenvector space and HadCM3 control for uncertainty testing and for using HadCM3 for both. Amplitudes are given for the best estimate and 5\%-95\% uncertainty limits are given in brackets. GAOL and NATURAL represent the scaling factors on the anthropogenic (greenhouse gases, aerosols, ozone, land use changes) and natural contributions from a combined analysis of ANTHRO and ALL. Where the signal is detected, scaling factors are shown in bold.

\begin{tabular}{|c|c|c|c|}
\hline Signal & $\operatorname{SNR}(\mathrm{Obs}=4.93)$ & Using HadGEM/HadCM3 & Using HadCM3/HadCM3 \\
\hline ANTHRO & 4.33 & $1.10(0.79,1.54)$ & $1.35(1.12,1.66)$ \\
\hline ALL & 4.38 & $1.12(0.82,1.54)$ & $1.18(0.99,1.42)$ \\
\hline GAOL & & $1.09(-15.24,11.53)$ & $0.93(-606.95,13.64)$ \\
\hline NATURAL & & $1.66(-107.24,108.25)$ & $2.66(-354.45,2340.26)$ \\
\hline
\end{tabular}




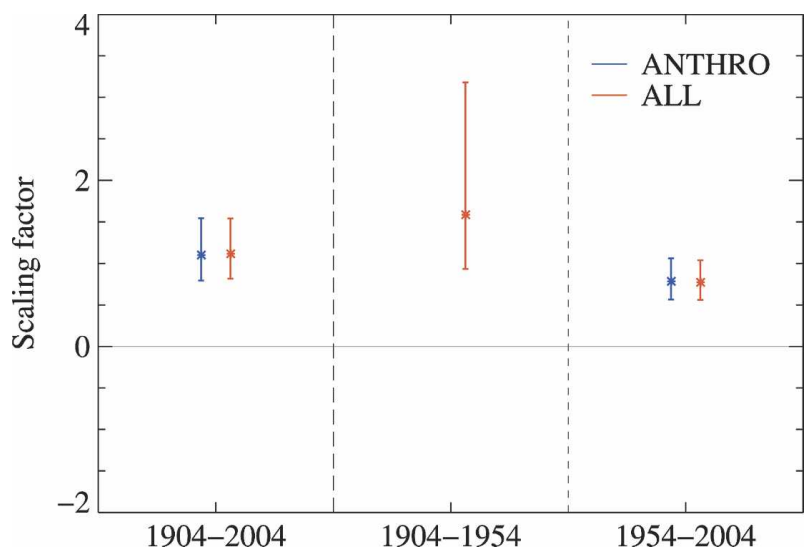

FIG. 10. Scaling factors for optimal detection analysis for the periods 1904-2004, 1904-54, and 1954-2004. The analysis produces unbounded confidence intervals for ANTHRO for the 1904-54 period and are therefore not shown.

agreement/disagreement should be interpreted with great caution. Recent research has highlighted large uncertainties in upper-air observations and the critical importance of considering both observational and model uncertainty in intercomparisons (Mears and Wentz 2005; Sherwood et al. 2005; Santer et al. 2005). Structural uncertainty is likely to dominate within the observations (Thorne et al. 2005a). However, in the present analysis we only consider published parametric (internal) uncertainties in HadAT2 (Thorne et al. 2005b). Caution should therefore be placed when making absolute inferences as to agreement or disagreement between models and observations. HadGEM1 and HadAT2 are both used within the larger observational/ model intercomparison undertaken for the Tropics by Santer et al. (2005).

Observed global mean time series are better matched

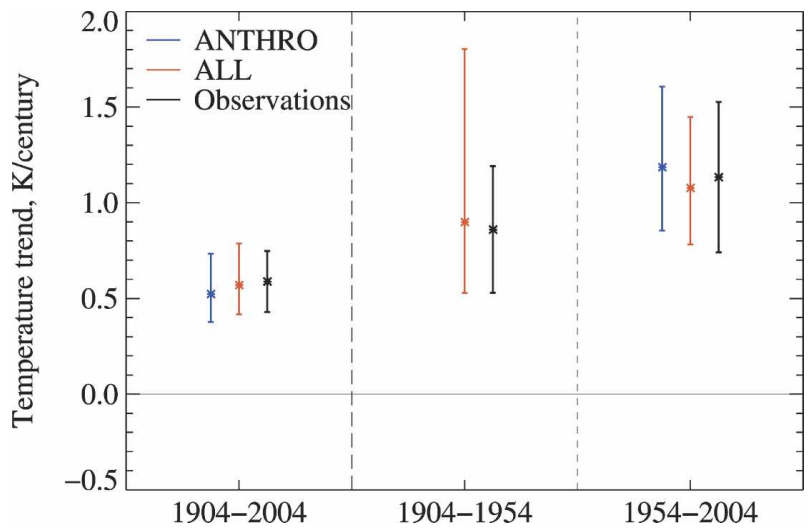

FIG. 11. Reconstructed scaled temperature trends (K century $^{-1}$ ) for the periods 1904-2004, 1904-54, and 1954-2004. The analysis produces unbounded confidence intervals for ANTHRO for the 1904-54 period and are therefore not shown. to ALL than to ANTHRO or any of the control segments in the stratosphere, the troposphere, and at the surface (Fig. 12). The addition of volcanic forcing improves the stratospheric time series (top panel) correspondence. Mt. Agung and El Chicón are well captured in both the timing and magnitude of their effects, while Mt. Pinatubo is less so; although this may be primarily related to timing of the quasi-biennial oscillation (Santer et al. 2005). Within the troposphere (center panel) there is a good degree of agreement between ALL simulations and the observations in long-term trend signs. Because HadGEM1 is a coupled model we would not expect it to capture ENSO timing except by chance, so there is poorer agreement on shorter time scales. The 1998 ENSO event effect in the observations is larger than any apparent ENSO activity in either the control or the forced runs. Surface time series (bottom panel) are in broad agreement with the earlier analysis. Subsampling has had only a minor impact on the time series.

Turning our attention to long-term trends, there remains considerable disagreement between the radiosonde dataset and the model (Table 3). Observations yield a consistent sign of accelerated cooling in the stratosphere over the satellite era, roughly double that for the whole period, and this cooling extends down to $200 \mathrm{hPa}$. The ALL simulation captures approximately the right magnitude of stratospheric cooling above 100 $\mathrm{hPa}$, but cooling does not extend as far down vertically as observed (Fig. 13). Within the troposphere the observations consistently yield less warming over the satellite era than the full radiosonde record. Thorne et al. (2005b) discuss this behavior in much further detail, finding that the time series could equally plausibly be described by a step change around the climate regime shift in the late 1970s. Seidel and Lanzante (2004) found similar behavior for other radiosonde-based datasets. In contrast, the model runs exhibit increasing warming with time (Table 3). The two exhibit tropospheric warming signals that are indistinguishable in the context of the control run variability. We therefore proceed to consider only the ALL runs to try to ascertain reasons for this divergent behavior.

Zonal mean trends yield fair agreement over the full period (Fig. 13, left-hand panels). Sampling is poor south of $45^{\circ} \mathrm{S}$, and both model and observational (Thorne et al. 2005b) uncertainties are large there. Within the troposphere, HadGEM1 has a warming signal that extends to higher altitudes than is evident in the observations, particularly in the Tropics. The ALL simulation exhibits an upper-tropospheric warming maximum that is not supported by the observations. Over the satellite era the agreement is much poorer 

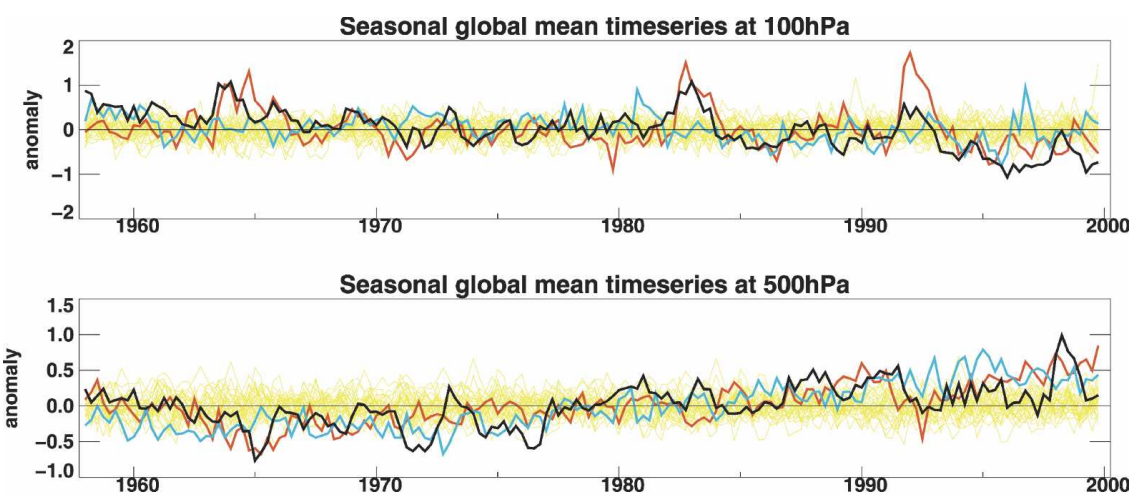

Seasonal global mean timeseries at $1.5 \mathrm{~m}$

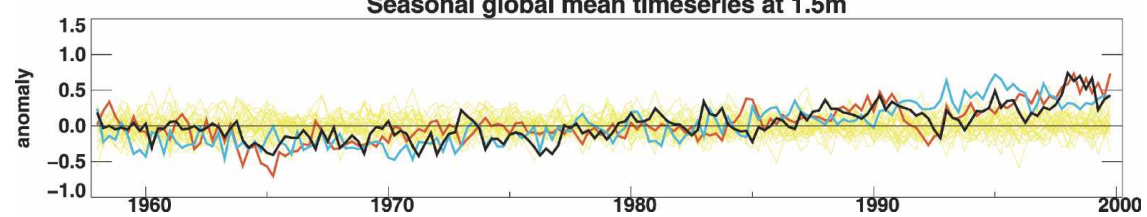

FIG. 12. Global seasonal mean temperatures for $100 \mathrm{hPa}, 500 \mathrm{hPa}$, and $1.5 \mathrm{~m}$ for observations (HadAT2/subsampled HadCRUT2v, black lines), model runs (ALL: red lines and ANTHRO: blue lines), and the 30 control segments (yellow lines).

(Fig. 13, right-hand panels), particularly in the Tropics. Sherwood et al. (2005) highlight large spurious tropical cooling in radiosondes in the Tropics because of daytime heating effects. Whether HadAT2 has successfully accounted for these requires further investigation. However, we speculate that any residual errors in HadAT2 might be toward cooling for this reason. Also, Santer et al. (2005) show that HadAT2 is toward the cool end of observational estimates in this region. Differences between observations and model simulations are generally largest in the Tropics and high latitudes where the observations are most uncertain.

\section{Projections of future warming to $\mathbf{2 2 0 0}$}

The global mean atmospheric surface temperature rise in the HadGEM1 simulations between 1961-90 and $2070-2100$ is approximately 3.4 and $3.8 \mathrm{~K}$ for the SRES A1B and A2 scenarios, respectively (Fig. 14). These projections are only slightly greater than those simulated for the same SRES scenarios in the earlier HadCM3 model (Johns et al. 2003), which were 2.9 and $3.3 \mathrm{~K}$, respectively, and are within the ranges reported in the IPCC Third Assessment Report for a wider range of climate models (1.9-3.6 K for A1B and 2.6-4.6 K for A2; Cubasch et al. 2001).

The rate of transient warming depends strongly on the applied forcing, the model's climate sensitivity, and the rate of ocean heat uptake. LOW05 report that the latter two parameters appear similar in HadGEM1 and HadCM3 for $1 \% \mathrm{yr}^{-1}$, increasing $\mathrm{CO}_{2}$ concentration simulations. However, the HadGEM1 scenario experiments reported here include extra forcing from black

TABLE 3. Decadal least squares linear fit trends $\left(\mathrm{K} \mathrm{decade}^{-1}\right)$ for observations (HadAT2/subsampled HadCRUT2v), model runs, and the 30 control segments. Trends are given for the periods 1958-99 (1979-99).

\begin{tabular}{|c|c|c|c|c|}
\hline Level & Observed & ANTHRO & ALL & Control range \\
\hline $30 \mathrm{hPa}$ & $-0.54(-1.12)$ & $-0.46(-0.53)$ & $-0.47(-0.60)$ & -0.07 to $0.07(-0.14$ to 0.20$)$ \\
\hline $50 \mathrm{hPa}$ & $-0.52(-0.99)$ & $-0.34(-0.36)$ & $-0.36(-0.51)$ & -0.08 to 0.08 ( -0.20 to 0.23$)$ \\
\hline $100 \mathrm{hPa}$ & $-0.23(-0.49)$ & $-0.08(-0.06)$ & $-0.06(-0.15)$ & -0.06 to $0.04(-0.10$ to 0.15$)$ \\
\hline $150 \mathrm{hPa}$ & $-0.05(-0.21)$ & $0.05(0.07)$ & $0.04(0.06)$ & -0.03 to 0.03 ( -0.11 to 0.08$)$ \\
\hline $200 \mathrm{hPa}$ & $0.06(-0.06)$ & $0.09(0.07)$ & $0.06(0.12)$ & -0.02 to 0.03 ( -0.07 to 0.07$)$ \\
\hline $300 \mathrm{hPa}$ & $0.14(0.14)$ & $0.25(0.29)$ & $0.19(0.33)$ & -0.05 to $0.06(-0.15$ to 0.14$)$ \\
\hline $500 \mathrm{hPa}$ & $0.12(0.09)$ & $0.22(0.29)$ & $0.16(0.28)$ & -0.05 to 0.06 ( -0.15 to 0.13$)$ \\
\hline $700 \mathrm{hPa}$ & $0.13(0.07)$ & $0.19(0.25)$ & $0.15(0.27)$ & -0.04 to 0.05 ( -0.09 to 0.12$)$ \\
\hline $850 \mathrm{hPa}$ & $0.15(0.10)$ & $0.15(0.21)$ & $0.11(0.26)$ & -0.04 to 0.05 ( -0.13 to 0.12$)$ \\
\hline $1.5 \mathrm{~m}$ & $0.12(0.19)$ & $0.18(0.29)$ & $0.14(0.27)$ & -0.05 to 0.06 ( -0.16 to 0.13$)$ \\
\hline
\end{tabular}



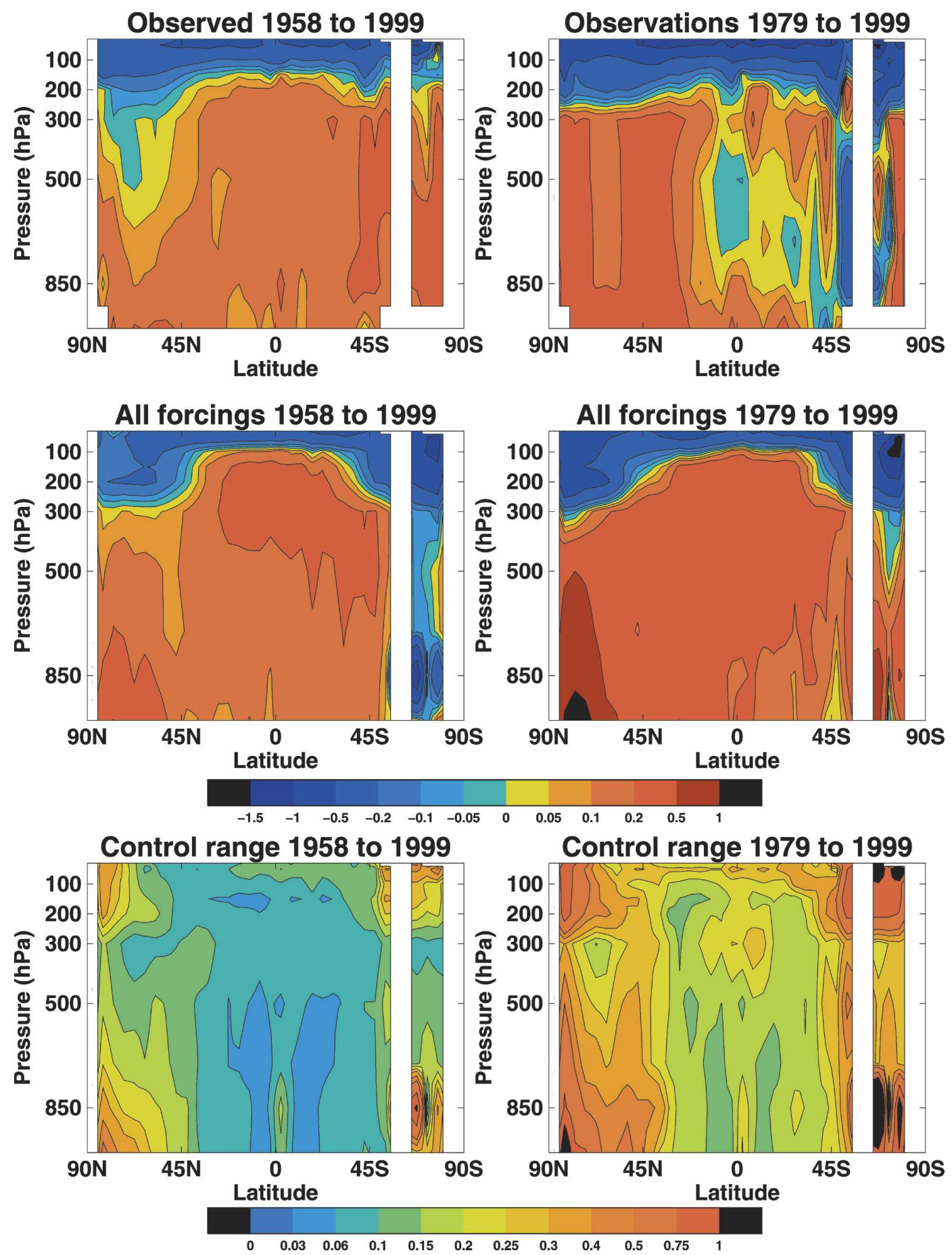

FIG. 13. Height-latitude cross-sectional temperatures trends for the periods 1958-99 and 1979-99 for observations (HadAT2, subsampled HadCRUT2v), the ALL model run, and the model range estimated from 30 control segments.

carbon, biomass burning, and land use changes, which may account for the slightly greater global mean warming in the HadGEM1 simulations.

The spatial pattern of surface warming during the twenty-first century in the HadGEM1 simulation (Fig. 15 , upper panel) contains many of the same features seen in a wide range of other GCM simulations (Cubasch et al. 2001), such as polar amplification and a 


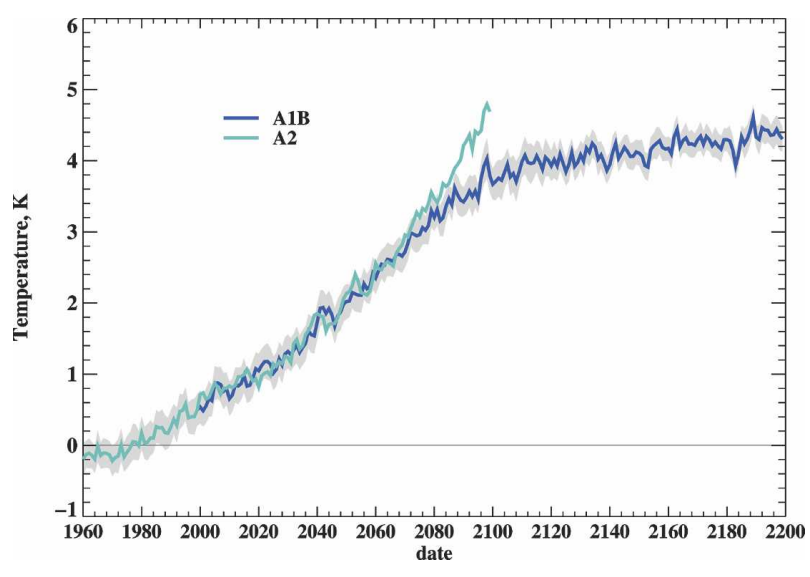

FIG. 14. Global annual mean 1.5-m temperature for ANTHRO, $\mathrm{A} 1 \mathrm{~B}$, and A2 simulations. Model temperatures are expressed as anomalies relative to the 1961-90 mean. A1B simulation is extended at 2100 keeping all forcings constant. Shaded regions represent twice the standard deviations of interannual variability calculated from HadGEM1 control.

greater warming of the land than the ocean. However, there are some differences between the models on regional scales, with the Arctic warming during the twentyfirst century generally being greater in HadGEM1 than HadCM3, while the warming over Western Europe, northern South America, and parts of Africa and the North Pacific is less in HadGEM1. This pattern of difference resembles that in LOW05 for a comparison of the two Hadley Centre models response to the same carbon dioxide-only forcing scenario. Thus, differences in local feedbacks appear to be the main cause of differences in patterns of warming response in the SRES experiments. The spatially varying forcing from the extra terms in the HadGEM simulation may also contribute, but we cannot estimate the magnitude of this contribution from the current set of experiments.

The thermal inertia of the climate system means that by 2100 the temperature response to the forcing applied during the twenty-first century will not have been fully realized. Indeed, there is a simulated imbalance of $1.8 \mathrm{~W} \mathrm{~m}^{-2}$ in the global average top-of-atmosphere net downward radiation when averaged over the period from 2090 to 2100 and measured relative to the parallel control experiment. The importance of the climate change commitment, and the fact that even if atmospheric greenhouse gas concentrations were fixed today, global mean temperatures and sea level would continue to rise, have been demonstrated in a simple climate model by Wigley (2005) and in a coupled general circulation climate model by Meehl et al. (2005). Wigley (2005) showed that the current commitment to future warming if concentrations are held constant could exceed $1 \mathrm{~K}$, and Meehl et al. (2005) showed that stabilization at 2000 levels would result in a further 0.5-K global warming according to their model.

The extension of the A1B scenario simulation, with fixed annual mean forcing from 2100 to 2200 , suggests a committed twenty-second-century warming of around $0.9 \mathrm{~K}$ when estimated using $30-\mathrm{yr}$ time averages from the end of the twenty-first and twenty-second centuries. However, if differences are measured between the final decade of each century, this is reduced to $0.7 \mathrm{~K}$. It is noteworthy that the rate of warming in Fig. 14 appears to slow relatively quickly after the stabilization of forcing, and in particular slows noticeably quicker than we have previously found using a simple two-layer model that was tuned to emulate the twenty-first-century warming of the more complex Hadley Centre GCMs. More work is required to understand the details of the differences in ocean warming and heat penetration between simple and complex models.

We have also examined the spatial distribution of warming in the twenty-second century in order to establish whether the pattern of committed warming differs from that of warming during the twenty-first century (Fig. 15, middle panel). Such differences could occur if the strength of local climate feedbacks changed over time (e.g., Senior and Mitchell 2000) or the pattern of total local radiative forcing changed significantly during the twenty-first century. It could be important for the planning of local long-term adaptation. In general, the twenty-second-century warming is found to follow a similar pattern as that of the twenty-firstcentury warming but is lower in magnitude. This would imply that the local feedbacks that determine the pattern of warming for a given forcing are not significantly different during the later period. However, it is also important to note that the twenty-second-century warming over a sizable region of the North Atlantic and Western Europe is not statistically significant (at the 2 sigma level), and changes may simply be because of natural variability in this region.

\section{Summary and discussion}

This paper has described the first transient simulations of climate change made with the new Hadley Centre climate model, HadGEM1. The model has many improvements over the previous Hadley Centre model, HadCM3, including a better representation of atmospheric dynamics, a higher resolution in atmosphere and ocean, and a fully interactive treatment of atmospheric aerosols. Johns et al. (2006) showed that the new model has a better simulation of present-day mean climate than that of $\mathrm{HadCM} 3$, as measured by a quasiobjective "climate index," although there are some de- 


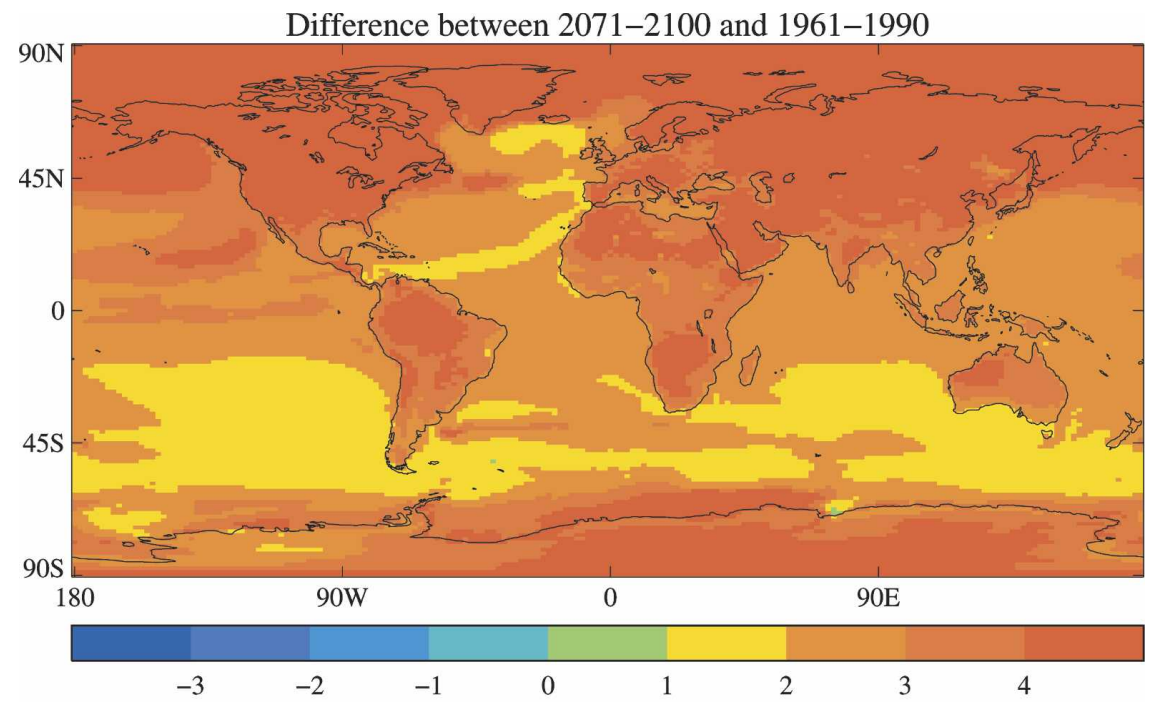

Difference between 2170-2199 and 2071-2100

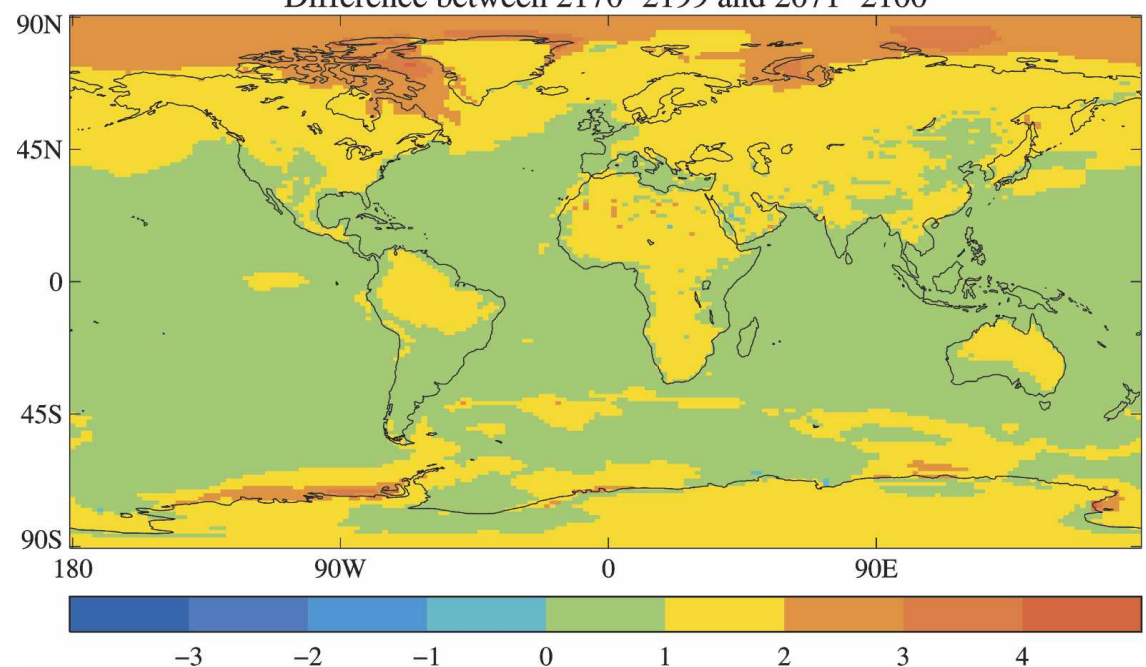

2 st dev calculated from HadGEM1 control

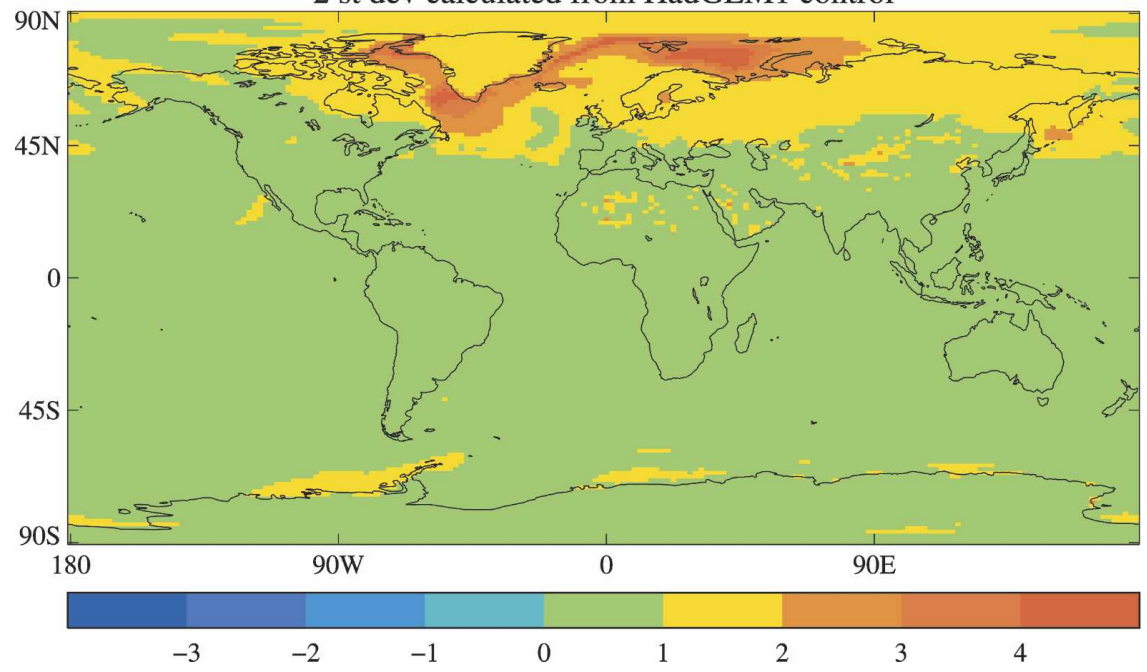

FIG. 15. Patterns of temperature change following the SRES A1B scenario with stabilization at 2100. Temperature change between (top) 2071-2100 and 1961-90 and (middle) 2170-99 and 2071-2100, and (bottom) 2 std devs of temperature change estimated from the HadGEM1 control simulation. 
ficiencies in its simulation of tropical climate and El Niño variability. In addition, the simulations described here include forcings that were not included in previous ensembles of twentieth-century HadCM3 simulations. Previously omitted forcings include black carbon and land use changes, although a multicentury simulation of HadCM3 has recently been made that includes land use changes and shows that deforestation from the early nineteenth century caused a drying of Northern Hemisphere land areas in the model (Tett et al. 2005, manuscript submitted to Climate Dyn.).

HadGEM1 is able to reproduce many aspects of the observed evolution of near-surface temperature both globally and on continental and subcontinental scales. An estimate of climate change over the twentieth century from natural factors alone (made by differencing HadGEM1 simulations with and without natural forcings) fails to produce the warming observed in recent decades. Applying an optimal detection analysis to model and observational data up to the end of 2004 updates previous analyses based on twentieth-century data only, and again finds a detectable signal of human influence on near-surface temperature changes over the previous $100 \mathrm{yr}$, when the anthropogenic fingerprint is estimated from HadGEM1.

These results support previous work using HadCM3 and other models that found compelling evidence for human influence on climate over the last century. They show that shortcomings in previous models, such as exclusion of black carbon and land use changes and the omission of a fully interactive aerosol scheme, does not compromise results accumulated by studies using many different climate models. Therefore, these results corroborate previous studies that support and strengthen the conclusions of the IPCC Third Assessment Report that "most of the global warming over the past 50 years is likely due to the anthropogenic increase in greenhouse gases" (Houghton et al. 2001; see International Ad Hoc Detection and Attribution Group 2005 for a review).

We have shown that discrepancies remain between model- and radiosonde-based estimates of the differential rates of warming at the surface and in the free troposphere since 1979. The omission of black carbon from model simulations could be part of the explanation, because black carbon aerosols tend to cool the surface and heat the troposphere, and any reductions in emissions of black carbon aerosols would therefore lead to greater warming at the surface than at the midtroposphere. However, our results indicate that the inclusion of black carbon aerosols does not resolve the discrepancy, at least for our model. While confidence in model-based detection results and predictions depends on rigorous testing of the models' ability to faithfully reproduce aspects of observed climate variability and change, it should be remembered that there remains considerable observational uncertainty associated with tropospheric temperature trends (Thorne et al. 2005a; Seidel and Lanzante 2004). To avoid ambiguity further model simulations and comparisons with other radiosonde- and satellite-based temperature records are required.

HadGEM1 simulations of twenty-first-century temperature changes following the SRES A2 and A1B scenarios predict slightly greater rates of warming than predictions made with the HadCM3 model. Because global mean warming for a carbon dioxide-only scenario has previously suggested a similar global mean warming in HadGEM1 relative to HadCM3, the extra forcings in the HadGEM1 policy-relevant scenarios appear to be leading to increased future warming. The spatial patterns of the extra forcings may contribute to different patterns of warming, but comparison between HadGEM1 and HadCM3 suggests this may be less than differences in local feedback strengths between the models.

A relatively small warming occurs during the stabilized forcing period of the twenty-second century when compared to the earlier twenty-first-century warming. It is likely that had the forcing been stabilized at year 2000, when the top-of-atmosphere net downward radiative imbalance was even smaller, the warming during stabilization would be even smaller, and less than either the A1B or A2 simulation up to 2050. This would imply that there is some scope for mitigating against future temperature rise over the next few decades. The pattern of commitment warming follows the same pattern of warming as the pattern of warming under increasing forcing, suggesting that local adaptation plans should account for committed warming. Furthermore, we find that there are no sizable areas with little twenty-firstbut large twenty-second-century commitment warming.

Acknowledgments. This work was funded by the U.K. Department of the Environment, Food and Rural Affairs under Contract PECD 7/12/37, by the GMR Programme, and the EU ENSEMBLES project. Historical and future forcing datasets for black carbon and biomass-burning aerosols were kindly provided by $\mathrm{T}$. Nozawa, NIES, Japan. Anthropogenic $\mathrm{SO}_{2}$ emissions data were kindly provided by S. J. Smith, PNNL, United States. The solar irradiance time series was kindly provided by S. Solanki and N. Krivova. We thank two anonymous reviewers for their helpful comments and the many Hadley Centre colleagues who de- 
veloped the HadGEM1 model and made this study possible.

\section{REFERENCES}

Alcamo, J., R. Leemans, and E. Kreileman, 1998: Global Change Scenarios of the 21st Century: Results from the IMAGE 2.1 Model. Elsevier, 308 pp.

Allen, M. R., and P. A. Stott, 2003: Estimating signal amplitudes in optimal fingerprinting, Part I: Theory. Climate Dyn., 21, 477-491.

Andres, R. J., and A. D. Kasgnoc, 1998: A time-averaged inventory of subaerial volcanic sulfur emissions. J. Geophys. Res., 103, 25 251-25 261.

Broccoli, A. J., K. W. Dixon, T. L. Delworth, T. R. Knutson, R. J. Stouffer, and F. Zeng, 2003: Twentieth-century temperature and precipitation trends in ensemble climate simulations including natural and anthropogenic forcing. J. Geophys. Res., 108, 4798, doi:10.1029/2003JD003812.

Bryan, K., 1969: A numerical method for the study of the circulation of the world ocean. J. Comput. Phys., 4, 347-376.

Collins, W., D. Stevenson, and C. Johnson, 1997: Tropospheric ozone in a global-scale three-dimensional Lagrangian model and its response to $\mathrm{NO}_{x}$ emissions. J. Atmos. Chem., 26, $223-$ 274.

Cox, M. D., 1984: A primitive equation, three dimensional model of the ocean. Ocean Group Tech. Rep. 1, GFDL, Princeton, NJ.

Cox, P. N., R. A. Betts, C. Bunton, R. Essery, P. Ronwtree, and J. Smith, 1999: The impact of new land surface physics on the $\mathrm{gcm}$ simulation of climate and climate sensitivity. Climate Dyn., 15, 183-203.

Cubasch, U., and Coauthors, 2001: Projections of future climate change. Climate Change 2001: The Scientific Basis, J. T. Houghton et al., Eds., Cambridge University Press, 525-582.

Daniel, J. S., S. Solomon, and D. L. Albritton, 1995: On the evaluation of halocarbon radiative forcing and global warming potentials. J. Geophys. Res., 100, 1271-1285.

Davies, T., M. J. P. Cullen, A. J. Malcolm, M. H. Mawson, A. Staniforth, A. A. White, and N. Wood, 2005: A new dynamical core for the Met Office's global and regional modelling of the atmosphere. Quart. J. Roy. Meteor. Soc., 131, 1759-1782.

Eddy, J., 1976: The maunder minimum. Science, 192, 1189-1202.

Frohlich, C., and J. Lean, 1998: The Sun's total irradiance: Cycles, trends and related climate change uncertainties since 1976. Geophys. Res. Lett., 25, 4377-4380.

Goldewijk, K. K., 2001: Estimating global land use change over the past 300 years: The HYDE database. Global Biogeochem. Cycles, 15, 417-433.

Gordon, C., C. Cooper, C. A. Senior, H. T. Banks, J. M. Gregory, T. C. Johns, J. F. B. Mitchell, and R. A. Wood, 2000: The simulation of SST, sea ice extents and ocean heat transports in a version of the Hadley Centre coupled model without flux adjustments. Climate Dyn., 16, 147-168.

Gray, L., J. Haigh, and R. Harrison, 2005: The influence of solar changes on the Earth's climate. Hadley Centre Tech. Note 62, $82 \mathrm{pp}$.

Houghton, J. T., Y. Ding, D. J. Griggs, M. Noguer, P. J. van der Linden, and D. Xiaosu, Eds., 2001: Climate Change 2001: The Scientific Basis. Cambridge University Press, $881 \mathrm{pp}$.

Hoyt, D. V., and K. H. Schatten, 1993: A discussion of plausible solar irradiance variations, 1700-1992. J. Geophys. Res., 98, 18 895-18 906.
International Ad Hoc Detection and Attribution Group, 2005: Detecting and attributing external influences on the climate system: A review of recent advances. J. Climate, 18, 12911314.

Johns, T. C., and Coauthors, 2003: Anthropogenic climate change for 1860 to 2100 simulated with the HadCM3 model under updated emissions scenarios. Climate Dyn., 20, 583-612.

- , and Coauthors, 2006: The new Hadley Centre climate model (HadGEM1): Evaluation of coupled simulations. J. Climate, 19, 1327-1353.

Jones, A., and D. L. Roberts, 2004: An interactive DMS emissions scheme for the Unified Model. Hadley Centre Tech. Note 47, $14 \mathrm{pp}$.

Jones, P. D., and A. Moberg, 2003: Hemispheric and large-scale surface air temperature variations: An extensive revision and an update to 2001. J. Climate, 16, 206-223.

Karoly, D., and K. Braganza, 2001: Identifying global climate change using simple indices. Geophys. Res. Lett., 28, 2205 2208.

Kettle, A. J., and Coauthors, 1999: A global database of seasurface dimethylsufide (dms) measurements and a procedure to predict sea surface dms as a function of latitude, longitude and month. Global Biogeochem. Cycles, 13, 399-444.

Kiehl, J. T., T. L. Schneider, R. W. Poltmann, and S. Solomon, 1999: Climate forcing due to tropospheric and stratospheric ozone. J. Geophys. Res., 104, 31 239-31 254.

Knight, J. R., R. J. Allan, C. K. Folland, M. Vellinga, and M. E. Mann, 2005: A signature of persistent natural thermohaline circulation cycles in observed climate. Geophys. Res. Lett., 32, L20708, doi:10.1029/2005GL024233.

Lean, J., 2000: Evolution of the sun's spectral irradiance since the maunder minimum. Geophys. Res. Lett., 27, 2425-2428.

_ J. Beer, and R. Bradley, 1995a: Reconstruction of solar irradiance since 1610: Implications for climate change. Geophys. Res. Lett., 22, 3195-3198.

_ O. White, and A. Skumanich, 1995b: On the solar ultraviolet spectral irradiance during the maunder minimum. Global Biogeochem. Cycles, 9, 171-182.

_ , Y.-M. Wang, and N. R. Sheeley Jr., 2002: The effect of increasing solar activity on the Sun's total and open magnetic flux during multiple cycles: Implications for solar forcing of climate. Geophys. Res. Lett., 29, 2224, doi:10.1029/ 2002GL015880.

Levitus, S., and Coauthors, 1998: World Ocean Database 1998. NOAA Atlas NESDIS 18, 346 pp.

Martin, G., M. Ringer, V. Pope, A. Jones, C. Dearden, and T. Hinton, 2006: The physical properties of the atmosphere in the new Hadley Centre Global Environmental Model (HadGEM1). Part I: Model description and global climatology. J. Climate, 19, 1274-1301.

Mears, C. A., and F. J. Wentz, 2005: The effect of diurnal correction on satellite-derived lower tropospheric temperature. Science, 309, 1548-1551.

Meehl, G. A., W. M. Washington, C. M. Ammann, J. M. Arblaster, T. M. L. Wigley, and C. Tebaldi, 2004: Combinations of natural and anthropogenic forcings in 20th century climate. J. Climate, 17, 3721-3727.

— - W. W. Collins, J. M. Arblaster, A. Hu, L. E. Buja, W. G. Strand, and H. Teng, 2005: How much more global warming and sea level rise? Science, 307, 1769-1772.

Montzka, S. A., J. H. Butler, J. W. Elkins, T. M. Thompson, A. D. Clarke, and L. T. Lock, 1999: Present and future trends in the 
atmospheric burden of ozone-depleting halogens. Nature, 398, 690-694.

Nakicenovic, N., and R. Swart, Eds., 2000: Emission Scenarios. Cambridge University Press, 570 pp.

Parker, D. E., L. V. Alexander, and J. Kennedy, 2004: Global and regional climate in 2003. Weather, 59, 145-152.

Randel, W. J., and F. Wu, 1999: A stratospheric ozone trends dataset for global modelling. Geophys. Res. Lett., 26, 30893092.

—, R. Stolarski, D. M. Cunnold, J. A. Logan, M. J. Newchurch, and J. M. Zawodny, 2003: Atmosphere-trends in the vertical distribution of ozone. Science, 285, 1689-1692.

Roberts, D. L., and A. Jones, 2004: Climate sensitivity to black carbon aerosol from fossil fuel combustion. J. Geophys. Res., 109, D16202, doi:10.1029/2004JD004676.

Robock, A., 2000: Volcanic eruptions and climate. Rev. Geophys., 38, 191-219.

Santer, B. D., and Coauthors, 1996: Human effect on global climate? Nature, 384, 522-525.

—- and Coauthors, 2005: Amplification of surface temperature trends and variability in the tropical atmosphere. Science, 309, 1551-1556.

Sato, M., J. E. Hansen, M. P. McCormick, and J. B. Pollack, 1993: Stratospheric aerosol optical depths (1850-1990). J. Geophys. Res., 98, 22 987-22 994.

_- J. Hansen, A. Lacis, and L. Thomason, cited 2002: Stratospheric aerosol optical thickness. NASA GISS Datasets and Images. [Available online at http://www.giss.nasa.gov/data/ strataer/.]

Seidel, D., and J. Lanzante, 2004: An assessment of three alternatives to linear trends for characterizing global atmospheric temperature changes. J. Geophys. Res., 109, D14108, doi:10.1029/2003JD004414.

Senior, C. A., and J. F. B. Mitchell, 2000: The time dependence of climate sensitivity. Geophys. Res. Lett., 27, 2686-2688.
Sherwood, S., J. Lanzante, and C. Meyer, 2005: Radiosonde daytime biases and late-20th century warming. Science, 309, $1556-1559$

Solanki, S., and N. Krivova, 2003: Can solar variability explain global warming since 1970? J. Geophys. Res., 108, 1200, doi:10.1029/2002JA009753.

Stott, P. A., 2003: Attribution of regional-scale temperature changes to anthropogenic and natural causes. Geophys. Res. Lett., 30, 1728, doi:10.1029/2003GL017324.

_ S. F. B. Tett, G. S. Jones, M. R. Allen, J. F. B. Mitchell, and G. J. Jenkins, 2000: External control of 20th century temperature by natural and anthropogenic forcings. Science, $\mathbf{2 9 0}$, 2133-2137.

- G. S. Jones, and J. F. B. Mitchell, 2003: Do models underestimate the solar contribution to recent climate change? $J$ Climate, 16, 4079-4093.

_ , J. F. B. Mitchell, J. M. Gregory, B. D. Santer, G. A. Meehl and T. L. Delworth, 2006: Observational constraints on past attributable warming and predictions of future global warming. J. Climate, 19, 3055-3069.

Tett, S. F. B., and Coauthors, 2002: Estimation of natural and anthropogenic contributions to twentieth century temperature change. J. Geophys. Res., 107, 4306, doi:10.1029/ 2000JD000028.

Thorne, P., D. Parker, J. Christy, and C. Mears, 2005a: Uncertainties in climate trends: Lessons from upper-air temperature records. Bull. Amer. Meteor. Soc., 86, 1437-1442.

,,-- S. Tett, P. Jones, M. McCarthy, H. Coleman, and P. Brohan, 2005b: Revisiting radiosonde upper air temperatures from 1958 to 2002. J. Geophys. Res., 110, D18105, doi:10.1029/ 2004JD005753.

Wigley, T. M. L., 2005: The climate change commitment. Science, 307, 1766-1769. 